Funders Report

\title{
Closing England's Maths Attainment Gap through One-to-One Tutoring - Global Solutions
}

Sweta Gupta and Mohamed Abouaziza

July 2021 
The Institute of Development Studies (IDS) delivers world-class research, learning and teaching that transforms the knowledge, action and leadership needed for more equitable and sustainable development globally.

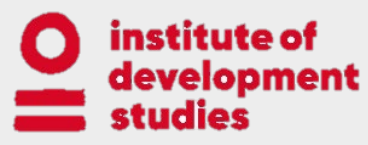

\author{
THIRD SPACE \\ LEARNING
}

(C) Third Space Learning, 2021

Closing England's Maths Attainment Gap through One-to-One Tutoring - Global Solutions

Sweta Gupta and Mohamed Abouaziza

July 2021

First published by the Institute of Development Studies in July 2021

DOI: $10.19088 /$ IDS.2021.050

A catalogue record for this publication is available from the British Library

All Rights Reserved

Available from:

Institute of Development Studies, Library Road

Brighton, BN1 9RE, United Kingdom

+44 (0)1273915637

ids.ac.uk

IDS is a charitable company limited by guarantee and registered in England

Charity Registration Number 306371

Charitable Company Number 877338 
Funders Report

\section{Closing England's Maths Attainment Gap through One-to-One Tutoring - Global Solutions}

Sweta Gupta and Mohamed Abouaziza

July 2021 


\section{Closing England's Maths Attainment Gap through One-to-One Tutoring - Global Solutions}

\section{Sweta Gupta and Mohamed Abouaziza}

July 2021

\section{Summary}

In the aftermath of COVID-related school closures in the UK, students lost two months of learning, but the loss among the 1.7 million disadvantaged students has been much larger at seven months. This disadvantaged gap is almost entirely driven by maths attainment. One-to-one tutoring is proven to be effective at helping students catch up, but private tutoring is most likely to be taken up by children from affluent households, further widening the disadvantaged gap in learning. This report discusses the feasibility of an innovative tutoring delivery model that uses the global graduate market to deliver tutoring at a scale that can solve this problem and a price that schools can afford. While the report discusses the overall opportunity that the emerging market economies of South- and South-East Asia provide, it also presents the Third Space Learning model in Sri Lanka as a case study to investigate the practicalities of the global online tutoring model.

\section{Keywords}

Education; Tutoring; Developing economies; Labour market trends

\section{Authors}

Sweta Gupta is a Research Officer at the Institute of Development Studies. She is a development economist with a focus on education, intra-household dynamics, gender, conflict. She has a Master's in Development Economics from the University of Oxford and a PhD in Economics from the University of Sussex. She has extensive experience working on policy evaluations in African countries and India, in partnership with NGOs, Governments, and International Organisations.

Mohamed Abouaziza is a PhD Economics Candidate at the University of Sussex with expertise in development economics. His current research revolves around credit constraints and relational contracts in various agricultural settings. Besides the PhD, he has worked with IFAD, FAO, LSE, and Heifer International on several impact evaluations in Rwanda, Chad, Kenya, and Uganda. 


\section{Executive Summary}

Most studies have put the learning loss due to COVID-related school closures in the UK as equivalent to two months, but the loss among the disadvantaged student group is much larger at seven months. This disadvantaged gap is almost entirely driven by maths attainment with the learning loss being 10-23 percent higher among disadvantaged students.

STEM subjects are vital for not only student achievement, attitude, interest, communication skills and problem-solving but also social mobility and economic development. Low numeracy skills represent a huge cost to society, estimated at $£ 20.2$ billion per year, or about 1.3 percent of the UK GDP. Add to this, an astronomical $£ 350 \mathrm{bn}$ in lost lifetime earnings across the 8.9 million school children due to the pandemic related learning loss.

In order to make up for the learning losses, the UK government launched the National Tutoring Programme (NTP) in the fall of 2020. Under the programme, schools can access subsidised 15-hour tutoring courses for disadvantaged pupils.

There is good evidence that one-to-one tutoring is effective. The Education Endowment Foundation systematic review finds that one-to-one tutoring over 6 to 12 weeks is effective, "delivering approximately five additional months' progress on average". Additionally, online tutoring provides a platform that gives students more control of their interactions and prompts learner reflection. Online tutoring can increase engagement among shy students as compared to face-to-face tutoring.

However, it is unlikely that the 15-hour tutoring block under the NTP can overcome the learning losses. A study by the Centre for Economic Performance estimates that at least 100 hours of tutoring over a year will be needed to compensate for the COVID-related learning losses. With the one-to-one tutoring cost at an average of $£ 46$ per hour under the NTP and 1.7 million Pupil Premium eligible students, this implies an investment of $£ 7.8$ billion. The Government's commitment to the NTP for the academic year $2021 / 22$ represents only 2.3 percent (or $£ 180$ million) of this $£ 7.8$ billion.

To provide tutoring as a scalable means of closing the attainment gap, the solution needs to be of a size and budget that the Government can support. The emerging economies of South- and South-East Asia provide a huge opportunity to tap into, for hiring tutors at affordable rates for students of all backgrounds in the UK.

- On average, 76 percent of the labour force have tertiary education with Vietnam, Indonesia, Sri Lanka, and Thailand having graduation rates higher than the 
average and comparable to the UK levels. The sheer number of this qualified workforce is $\mathbf{5 3 7}$ million individuals with at least a bachelor's degree.

- 28 percent of the graduates in these countries specialise in the STEM subjects, a percentage higher than the UK's proportion of STEM graduates.

- Despite the highly qualified labour market, the unemployment rates remain high at 7 percent, implying that there are an estimated 56 million graduates located across the emerging economies of South- and South-East Asia who are without an income. Hiring the highly qualified workforce from these countries to serve as online tutors could help achieve equitable social impact.

- The average monthly salary in these countries is one-tenth of that in the UK, implying that serving as online tutors in the UK is an economically lucrative prospect. These graduates can be offered tutor pay that is competitive in the domestic market, whilst also keeping the costs low in the UK.

- With the developments in communication technology, there is an opportunity to connect UK students with tutors online quite easily. On average 65 percent of the population across these countries have access to the internet with SouthEast Asian countries having higher than the average levels of internet penetration. Internet coverage continues to grow and has expanded by 45 percent in the last 5 years. At this pace, one would expect near-universal coverage by 2026 .

- According to Education First, these countries also have moderate to high levels of English-speaking ability, particularly in Malaysia and the Philippines, where the English-speaking abilities are at par with the countries of continental Europe.

Using the Third Space Learning (TSL) tutor model in Sri Lanka as a case study, we provide examples and evidence of how the qualified English-speaking labour force can be trained to provide tutoring support in the UK. TSL was established in 2013 to bring affordable one-to-one tutoring in maths to UK schools, particularly the disadvantaged schools. TSL has delivered tutoring sessions to over 90,000 students in over 2,800 state schools, 45 percent of whom were eligible for Pupil Premium.

- TSL has increased its number of tutors phenomenally in response to an increase in demand from UK schools in 2020-2021. Between January 2021 and May 2021, TSL hired 513 tutors in Sri Lanka from an application pool of 13,844 , which is a selection rate of only 3.7 percent.

- The tutors are hired through an intensive 6-stage interview process which involves extensive background checks, maths and English tests, personalitybased interviews, teaching skills-based interviews, and a 46-hour initial tutor training (ITT). 
- While there is no formal requirement that tutors need any training/certification in the UK, the ITT provided by TSL is intense at 46 hours over three weeks. The Level 3 Award in Tutor Training Theory 'PRESET' provided by Myelin Academia and the Level 3 Qualification for Tutors provided by Qualified Tutor are the most widely used tutor certifications, also endorsed by the Tutor's Association in the UK. While the former is an 8-hour course at a cost of $£ 120$ to the tutor, the latter is a 32-hour course at a cost of $£ 260$ to the tutor. As such, the ITT provided by TSL is longer than these UK-based certifications and comes at no cost to the tutors themselves. In fact, tutors are compensated for their ITT participation.

- Along with the ITT, TSL continues to invest in its tutors through Continuous Professional Development. This takes the form of regular feedback sessions set up by Academic Coaches. Each Academic Coach mentors 30 tutors and provides weekly feedback. During the feedback, tutors reflect on their strengths and areas of improvement. This forms the basis for regular refresher training tailored to the tutor's needs.

- Tutoring sessions are also randomly selected for performance evaluations. The evaluations are conducted twice per academic term and are based on the tutor's familiarity with TSL safeguarding procedures, subject knowledge, communication skills, and student-centred teaching.

- All tutoring sessions are recorded for safeguarding purposes. Safeguarding policies ensure that each tutor is verified through police records and reference checks. Furthermore, every tutor undergoes training on safeguarding policies as part of the ITT and refresher training throughout the academic year.

- The tutors themselves are highly qualified and bring high levels of skills into the job - 67 percent specialise in STEM or maths-related subjects at university.

- The primary motivation for joining TSL is an opportunity for young adults to earn an income to support their studies and to also gain work experience. Additionally, women tutors value the part-time nature and the flexibility to work remotely.

- 84 percent of the tutors appreciate the pay structure and benefits that the TSL provides. At an average of $£ 3.07$ per hour, the TSL tutor pay is a significant premium over the local labour market pay. This is estimated at 2.8 times the average local salary for skilled and semi-skilled workers.

- An overwhelming result of this case study is the high levels of satisfaction among TSL tutors with training and feedback, communication with management and overall job satisfaction. At least 94 percent are satisfied with the level of training and feedback; at least 85 percent are satisfied with their communication with the management; and at least 90 percent are overall satisfied with working at TSL. 


\section{Contents}

Acronyms

1. Introduction

2. Opportunities in the Emerging Markets of South- and South-East Asia

3. Evidence from Case Study: Third Space Learning in Sri Lanka

3.1 Hiring, Initial Training, and Continuous Professional Development

3.2 Performance Evaluation

3.3 Safeguarding

3.4 Tutor Qualifications

3.5 Tutor Motivation

3.6 Tutor Pay

3.7 Work Environment and Tutor Satisfaction

4. Conclusion 
Figures

Figure 1: Labour force with tertiary education

Figure 2: Graduates from STEM programmes in tertiary education

Figure 3 Unemployment rate among those with tertiary education

Figure 4: Average monthly salary in GBP

Figure 5: English proficiency

Figure 6: Internet usage

Figure 7: Cumulative number of tutors joining TSL in Sri Lanka

Figure 8: Hiring journey at TSL in Sri Lanka

Figure 9: Tutor session evaluation score (out of 100) by performance pillars

Figure 10: Educational Qualifications of TSL tutors in Sri Lanka

Figure 11: Tutor motivation to work at TSL in Sri Lanka

Figure 12: Tutor perception of flexibility at TSL in Sri Lanka

Figure 13: Tutor perception of pay at TSL in Sri Lanka

Figure 14: Tutor perception of training and feedback at TSL in Sri Lanka

Figure 15: Tutor perception of communication within TSL in Sri Lanka

Figure 16: Tutor perception of job satisfaction at TSL in Sri Lanka

\section{Tables}

Table 1: Performance pillars from tutor's session evaluation at TSL in Sri Lanka 


\section{Acronyms}

$\begin{array}{ll}\text { CPD } & \text { Continuing Professional Development } \\ \text { EF } & \text { Education First } \\ \text { EPI } & \text { English Proficiency Index } \\ \text { HLO } & \text { Harmonized Learning Outcomes } \\ \text { ITT } & \text { Initial Tutor Training } \\ \text { NFER } & \text { National Foundation for Educational Research } \\ \text { NSPCC } & \text { National Society for the Prevention of Cruelty to Children } \\ \text { OECD } & \text { Organisation for Economic Co-operation and Development } \\ \text { PPP } & \text { Purchasing Power Parity } \\ \text { STEM } & \text { Science, Technology, Engineering and Mathematics } \\ \text { TIMSS } & \text { Trends in International Mathematics and Science Study } \\ \text { TSG } & \text { Third Space Global } \\ \text { TSL } & \text { Third Space Learning }\end{array}$




\section{Introduction}

Education is a key determinant of human capital, labour productivity and economic growth. The Science, Technology, Engineering and Mathematics (STEM) subjects are particularly vital for not only student achievement, attitude, interest, communication skills and problem-solving but also social mobility and economic development (Kara, Tonin and Vlassopoulos, 2021). Additionally, the Department for Business, Energy \& Industrial Strategy (2017) reports that STEM jobs are expected to rise at double the rate of other occupations.

Yet, 40 percent of employers in the UK find the shortage of STEM graduates a key barrier. Low numeracy skills also represent a huge cost to society, estimated at $£ 20.2$ billion per year, or about 1.3 percent of the UK GDP (Menzies, Ramaiah and Boulton, 2021).

This STEM crisis has been further exacerbated by the COVID-related school closures reflecting both social and economic consequences. While most studies have put the learning loss among primary school students at equivalent to two months, the loss among the disadvantaged student group is much larger at seven months. This disadvantaged gap is almost entirely driven by maths attainment with the learning loss being 10-23 percent higher among disadvantaged students. ${ }^{1}$ The Institute of Fiscal Studies predicts that the learning loss equates to an astronomical $£ 350 \mathrm{bn}$ in lost lifetime earnings across the 8.9 million school children in the UK (Sibieta, 2020).

While education moved abruptly online in March 2020 at the start of the pandemic in the UK, teachers struggled to keep up with the curriculum - 80 percent reported covering less than usual (Lucas et al., 2020). Teachers reported that, on average, just over half of their pupils' parents were engaged with their children's home learning. The parental engagement was significantly lower in the most deprived schools (Lucas et al., 2020).

As we look for solutions, it is important to reflect that the country's teachers are significantly overworked. Teachers in the UK, on average work 46 hours a week, longer than their OECD counterparts and for 25-30 percent lower salaries than teachers working similar hours in the United States and Canada. ${ }^{2}$ According to the 2021 annual report on the Teacher Labour Market in England by the National Foundation for Educational Research (NFER), the workload negatively affects teachers' satisfaction levels compared to professionals working similar hours. The pandemic has only exacerbated the situation, leading to an increased level of anxiety and lower levels of happiness and life satisfaction among teachers (Worth

\footnotetext{
${ }^{1}$ See the evidence compiled by the Education Endowment Foundation

2 See the article published by The Economist
} 
and Faulkner-Ellis, 2021). Thus, using teachers as tutors to provide support to disadvantaged students will only exacerbate the teachers' hardships.

In order to make up for the learning losses, teachers should be supported with supplementary tutors. This need has been recognised by the Government, which led to the launch of the National Tutoring Programme (NTP) in the fall of 2020. Under the programme, schools can access subsidised 15-hour tutoring courses for disadvantaged pupils.

There is good evidence that one-to-one tutoring is effective. The Education Endowment Foundation systematic review finds that one-to-one tutoring over 6 to 12 weeks is effective, "delivering approximately five additional months' progress on average". ${ }^{3}$ Private tutoring is a prevalent phenomenon in both developing and developed countries. For instance, Mischo and Haag (2002) conclude that private tutoring in Luxembourg enhanced school performance and motivational factors such as self-concept of ability and learning incentives. Along the same line, Davies (2004) reports that parents in Canada consider private tutoring as an affordable alternative to private schools, and it does not necessarily reflect their satisfaction with public education.

A meta-analysis of studies comparing blended teaching (online combined with face-to-face classroom teaching) with just face-to-face teaching, on average found a positive impact on learning outcomes from the former (Means et al., 2009). With the ICT revolution, online tutoring provides a platform that gives students more control of their interactions and prompts learner reflection. Ciano (2007) studying the US market for tutoring, argues that online tutoring can increase engagement among shy students as compared to face-to-face tutoring.

Despite the rich evidence on the benefits of supplementary tutoring, the take-up in the UK remains lower than in most high-income countries. In 2019, the Department for Education reported that 17 percent of England's year 9 pupils attended additional mathematics tuition outside of school. In science, this was 10 percent of pupils. In both cases, the percentages were below the international average, and the six highest-performing countries on TIMSS had the highest percentages of pupils attending additional tutoring, ranging from Russia at 35 percent to the Republic of Korea at 78 percent (Richardson et al., 2020). ${ }^{4}$

An important constraint to the take-up of private tutoring in the UK is the costs - 60 percent of the parents in a survey conducted by Ireson and Rushforth (2014) stated the expensive nature of tutoring to be one of the most important hindrances in the take up of private tutoring for their children. Relatedly, those who do take up private tuition in the UK come from affluent families, with highly educated parents

\footnotetext{
${ }^{3}$ See the systematic review conducted by the Education Endowment Fund.

4 The TIMSS (Trends in International Mathematics and Science Study) test is used to compare the performance of students in Mathematics and Science across countries.
} 
(Menzies, Ramaiah and Boulton, 2021). Thus, tutoring must be affordable to ensure social mobility. With continued improvements in communication technology, Ciano (2007) suggests that an online tutor based in India charges the US-based students at least less than a third of what they would pay for online or face-to-face tutors based in the US.

To provide tutoring as a scalable means of closing the attainment gap, the solution needs to be of a size and budget that the Government can support, particularly as families from poorer backgrounds cannot afford the tuition that their wealthier peers often resort to. Even if only the 1.74 million Pupil Premium eligible pupils were to access the 15-hour tutoring courses, this would require over 26 million hours of tutor time (Menzies, Ramaiah and Boulton, 2021). Given the existing constraints on teachers, it is hard to see, within the existing domestic tutor models, where this tutor capacity can come from.

Additionally, it is unlikely that the 15-hour tutoring block under the NTP can overcome the learning losses. A study by the Centre for Economic Performance estimates that at least 100 hours of tutoring over a year will be needed to compensate for the COVID-related learning losses (Eyles, Gibbons, and Montebruno, 2020). With the one-to-one tutoring cost at an average of $£ 46$ per hour under the NTP and 1.7 million Pupil Premium eligible students, this implies an investment of $£ 7.8$ billion. ${ }^{5}$ The Government's commitment to the NTP for the academic year $2021 / 22$ represents only 2.3 percent (or $£ 180$ million) of this $£ 7.8$ billion. ${ }^{6}$

This report discusses the feasibility of an innovative tutoring delivery model that uses the global market to solve the supply constraint within the UK domestic market and to deliver scale at a cost that schools and the UK Government can afford. While we discuss the overall opportunity that certain Asian economies provide in delivering tutoring, we also present the Third Space Learning (TSL) model in Sri Lanka as a case study to investigate the practicalities of the global online tutoring model.

\footnotetext{
${ }^{5}$ The average tutoring cost per hour is calculate using the NTP Tuition Partners who provide 1:1 tutoring. Where in-person and online tutoring rates were different, the lower of the two was used for calculation.

${ }^{6}$ See NTP funding plan for AY 2021/22.
} 


\section{Opportunities in the Emerging Markets of South- and South-East Asia}

A potential route to look for qualified tutors is harnessing the skills of a highly qualified labour force in the emerging economies of South- and South-East Asia. ${ }^{7}$ According to the 2020 Harmonized Learning Outcomes (HLO) database developed by the World Bank, while the average years of schooling in India are 11 years, all other emerging economies of South- and South-East Asia are at par with the developed high-income countries with 13 years of school (Angrist et al., 2021). But what is truly remarkable is the level of education beyond secondary school (see Figure 1). Based on the International Labor Organization estimates, all emerging economies in this region have a majority population with at least a bachelor's degree or higher. Countries such as Sri Lanka, Indonesia, Thailand, and Vietnam are at par with the UK, if not better. Even with 60 percent of the labour force with an advanced degree in India, the sheer number of this qualified workforce stands at 296 million individuals, a number 10 times that of the UK's qualified workforce of 29 million. 


\section{Figure 1: Labour force with tertiary education}
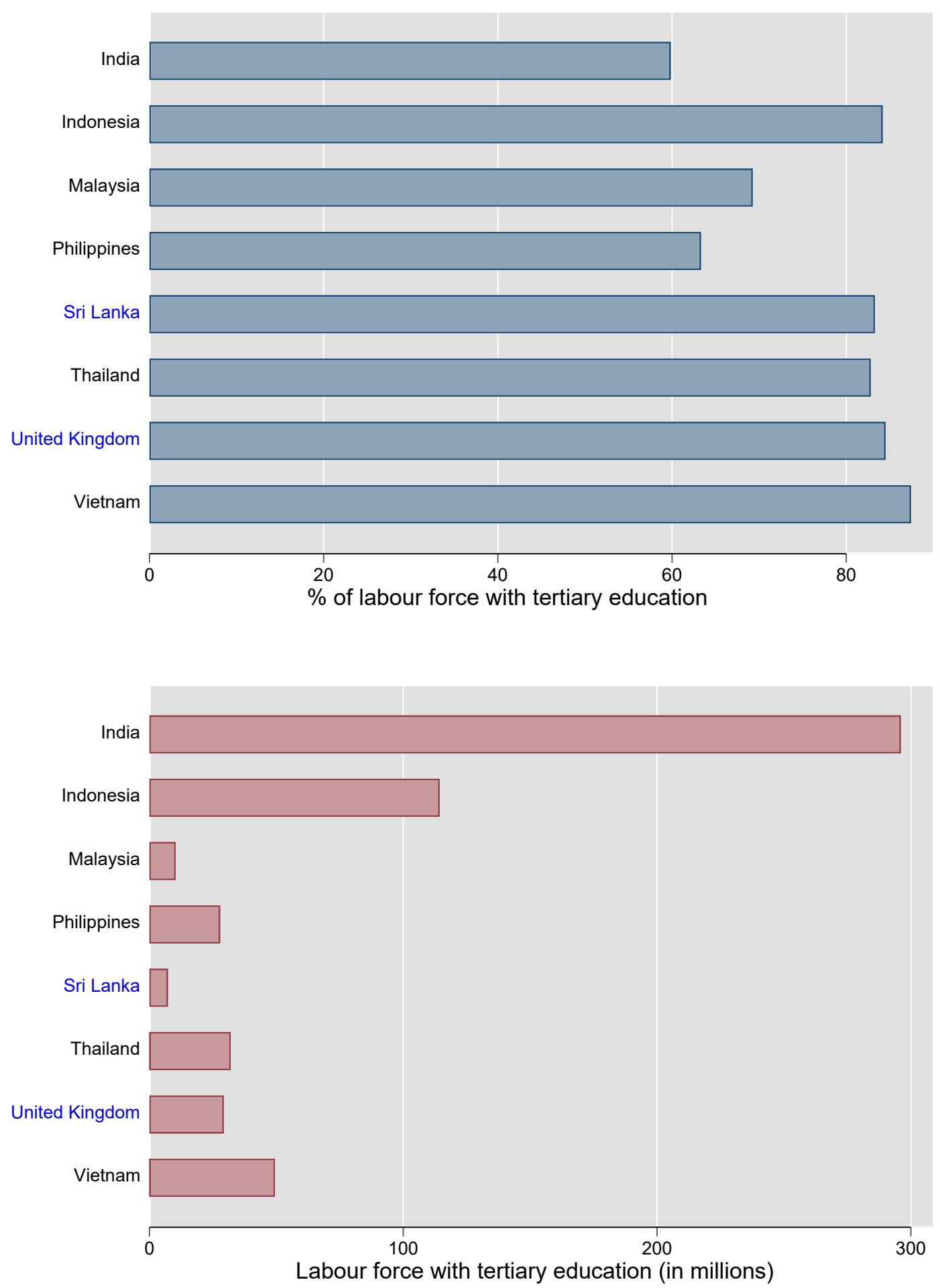

Source: Author's calculations based on the International Labor Organisation, ILOSTAT database accessed on World Bank Databank website on 25 June 2021. The figure is based on measures from 2019, except for Vietnam where the year is 2020, Sri Lanka where the year is 2018, Philippines where the year is 2016, and Malaysia where the year is 2016 . 
Given this highly qualified global labour market, it is unsurprising that India is considered an online hub to deliver affordable tutoring to students in the US (Ciano, 2007). Such a setting represents a win-win situation for both the supply (tutors in India) and the demand (students in the US). One of the reasons for India's comparative advantage in the tutoring industry is the high proportion of Indian graduates in the STEM disciplines. India with 33 percent of the students graduating from STEM disciplines, is one the largest producers of STEM graduates in the world. However, a closer look at other emerging market economies of South- and South-East Asia shows that countries like Malaysia, the Philippines, and Thailand have a substantial proportion of STEM graduates, higher than that of the UK (see Figure 2).

\section{Figure 2: Graduates from STEM programmes in tertiary education}

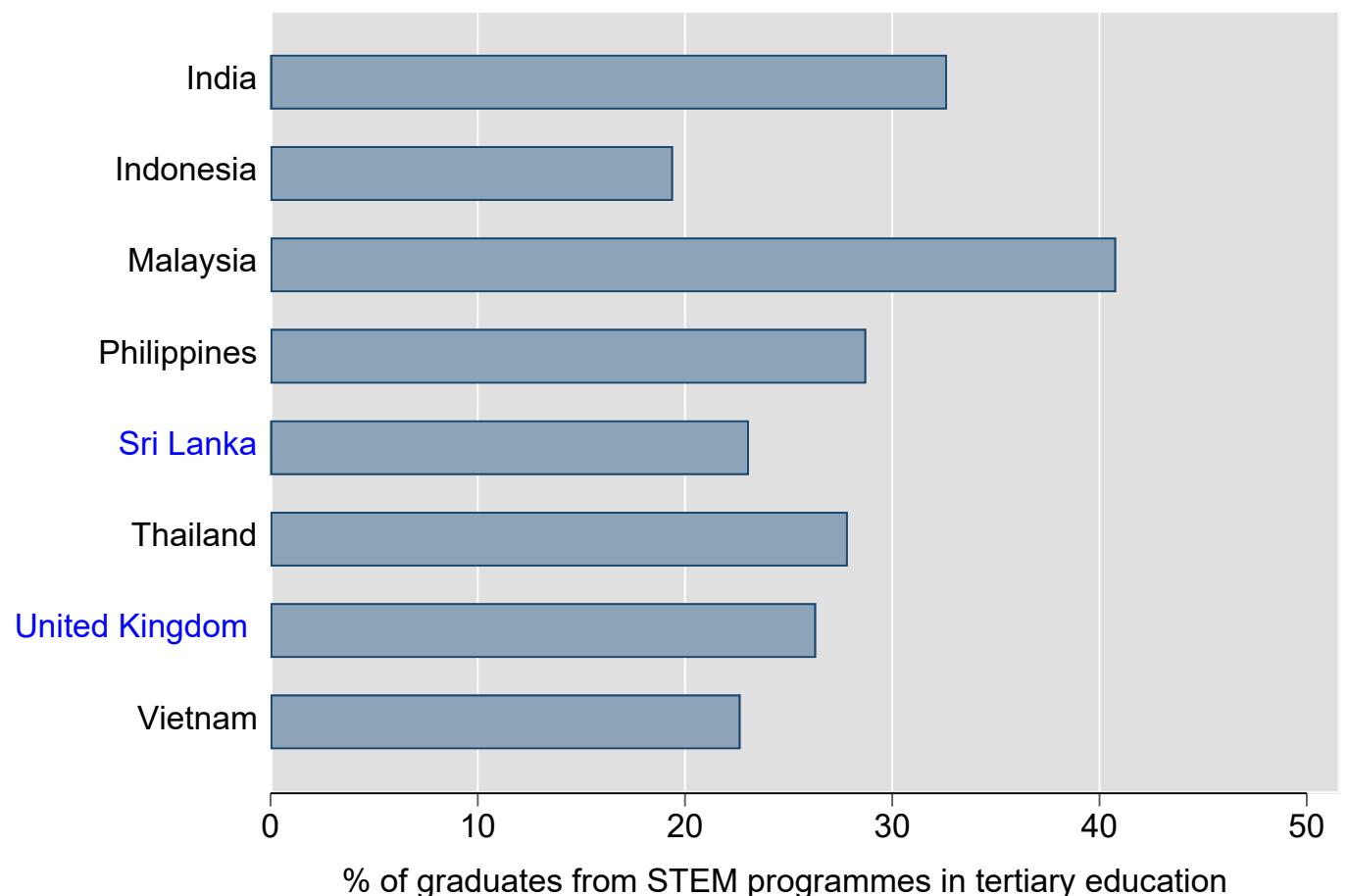

Source: Authors' calculations based on UNESCO database accessed on World Bank Databank website on 25 June 2021, except for Sri Lanka where the information comes from the Sri Lanka University Grants Commission. The figure is based on the latest data available - 2018 for India, Indonesia, Malaysia, Sri Lanka; 2017 for the Philippines; and 2016 for Thailand, Vietnam and the United Kingdom.

While the region has a huge demographic dividend with highly qualified youth entering the labour market, the countries have struggled to provide adequate job opportunities domestically. This is reflected in the high unemployment rates among individuals with advanced university degrees. Figure 3 shows that the unemployment rates among those with advanced degrees are higher in almost all the South and South-East Asian emerging economies (except Thailand) 
compared to the UK. The unemployment rates are higher in India (15 percent), Sri Lanka (8.5 percent) and the Philippines (7.5 percent), compared to 2.5 percent in the UK. To put this in perspective, there are at least 56 million individuals in the emerging economies of South- and South-East Asia with at least a bachelor's degree or higher, who have no source of income or employment.

\section{Figure 3 Unemployment rate among those with tertiary education}

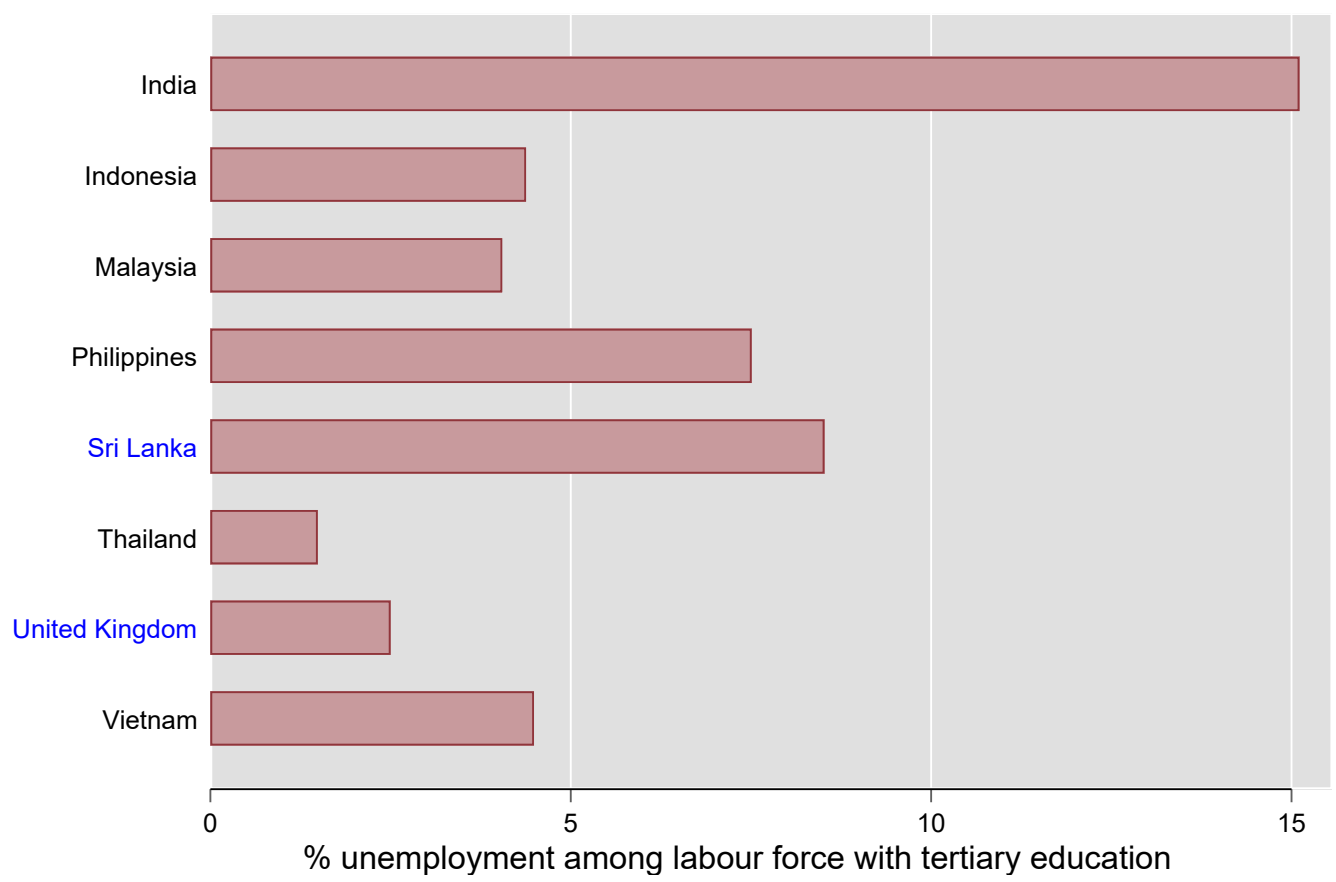

Source: Author's calculations based on the International Labor Organisation, ILOSTAT database accessed on World Bank Databank website on 25 June 2021. The figure is based on measures from 2019, except for Vietnam where the year is 2020, Sri Lanka where the year is 2018, Philippines where the year is 2016, and Malaysia where the year is 2016 .

Even for those who are employed in regular full-time skilled and semi-skilled occupations, the monthly wages are overwhelmingly low as compared to the UK both in absolute terms as well as using Purchasing Power Parity (PPP) comparisons (see Figure 4). The average monthly salary in the UK was $£ 2,280$ in April 2021 (Office of National Statistics). Converted to GBP, the average monthly salary in South- and South-East Asia of full-time skilled and semi-skilled workers is a tenth of the salary in the UK, except for Malaysia and Thailand. Even in terms of PPP, the monthly pay in these countries is a quarter of that of the UK. Malaysia comes close to the UK average pay at £2,030 (PPP adjusted), while Thailand's salaried workers earn half of the UK average pay at $£ 1,041$ (PPP adjusted). Given the domestic pay structure, it is understandable why graduates may find providing 
online tutoring to students in high-income countries a lucrative opportunity. For instance, a recent job advertisement by Trivium Education, a company that hires online tutors from India for US-based students, offered an estimated monthly salary of $£ 150$ for part-time tutoring (15 hours/week), a salary that is almost equivalent to what full-time workers in India earn as shown in Figure $4 .^{8}$

\section{Figure 4: Average monthly salary in GBP}

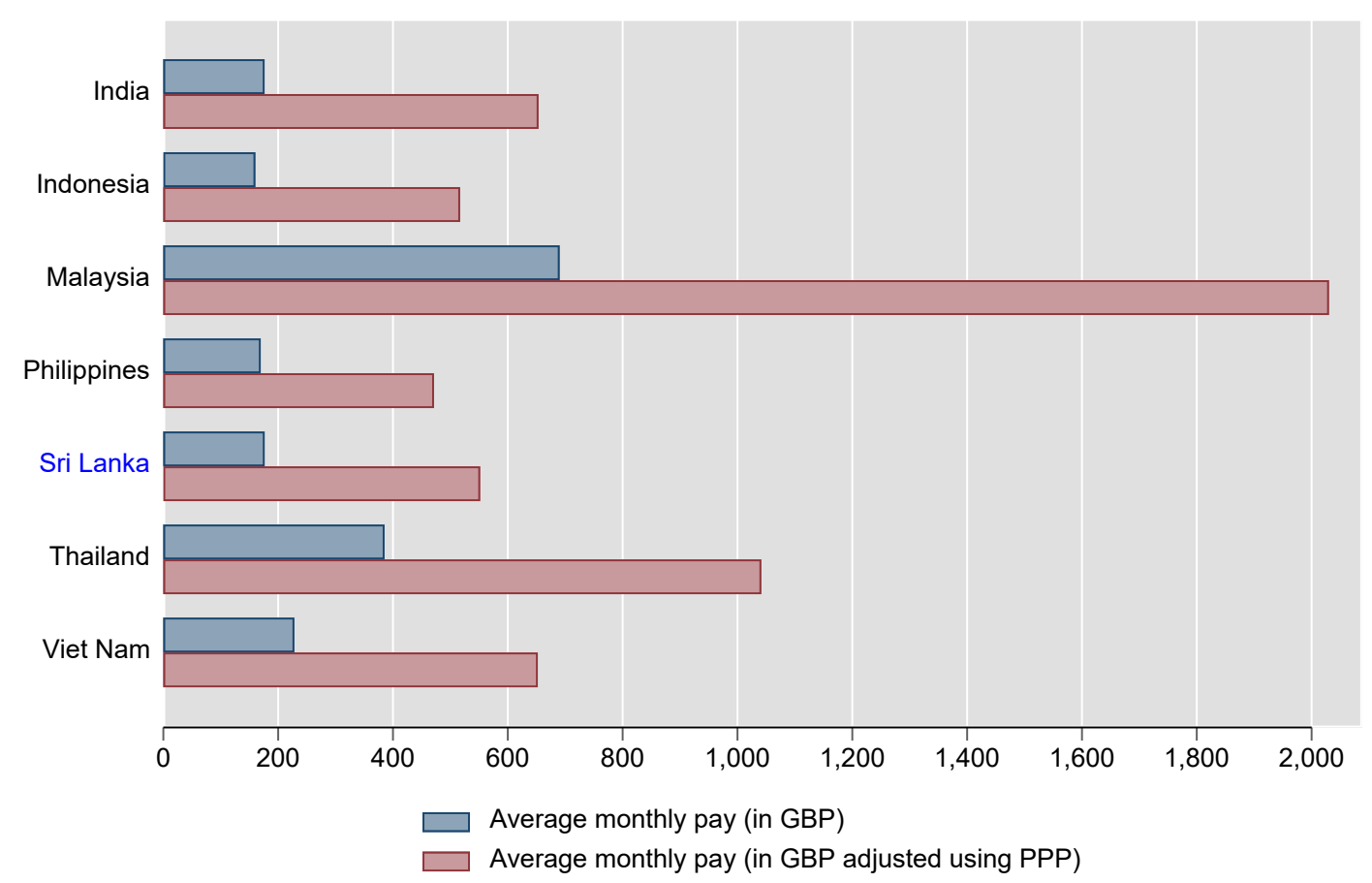

Source: Author's calculations based on individual sources of database available at the country level and for the latest year available. India: 2019 India Ministry of Statistics and Programme Implementation: Periodic Labour Force Survey; Indonesia: 2019 Statistics Indonesia of the Republic of Indonesia; Malaysia: 2019 Department of Statistics of Malaysia; Philippines: 2018 National Statistical Office of the Philippines; Sri Lanka: 2019 Department of Census and Statistics: Labour Force Survey; Thailand: 2019 National Statistical Office of Thailand; Vietnam: 2019 General Statistics Office of Vietnam. The PPP calculation is based on the data from Our World in Data.

Besides the academic qualifications, tutors in South- and South-East Asia have an advantage when it comes to English language skills. This is something that is not guaranteed in many developing countries (Education First, 2020). Figure 5 illustrates the Education First English Proficiency Index (EF EPI) in our countries of interest, with an average EF EPI score of 488 out of a total of 800 points. ${ }^{9}$ While India and Sri Lanka perform close to the average at 496 and 466 respectively,

\footnotetext{
${ }^{8}$ The salary range was estimated by Glassdoor and the job was advertised on this link.

9 The EF EPI is based on test data from more than 2,200,000 test takers around the world who took the EF Standard English Test (EF SET) or one of our English placement tests in 2019.
} 
South-East Asian countries like Malaysia and the Philippines perform at least as well as other continental European countries on the EF EPI.

\section{Figure 5: English proficiency}

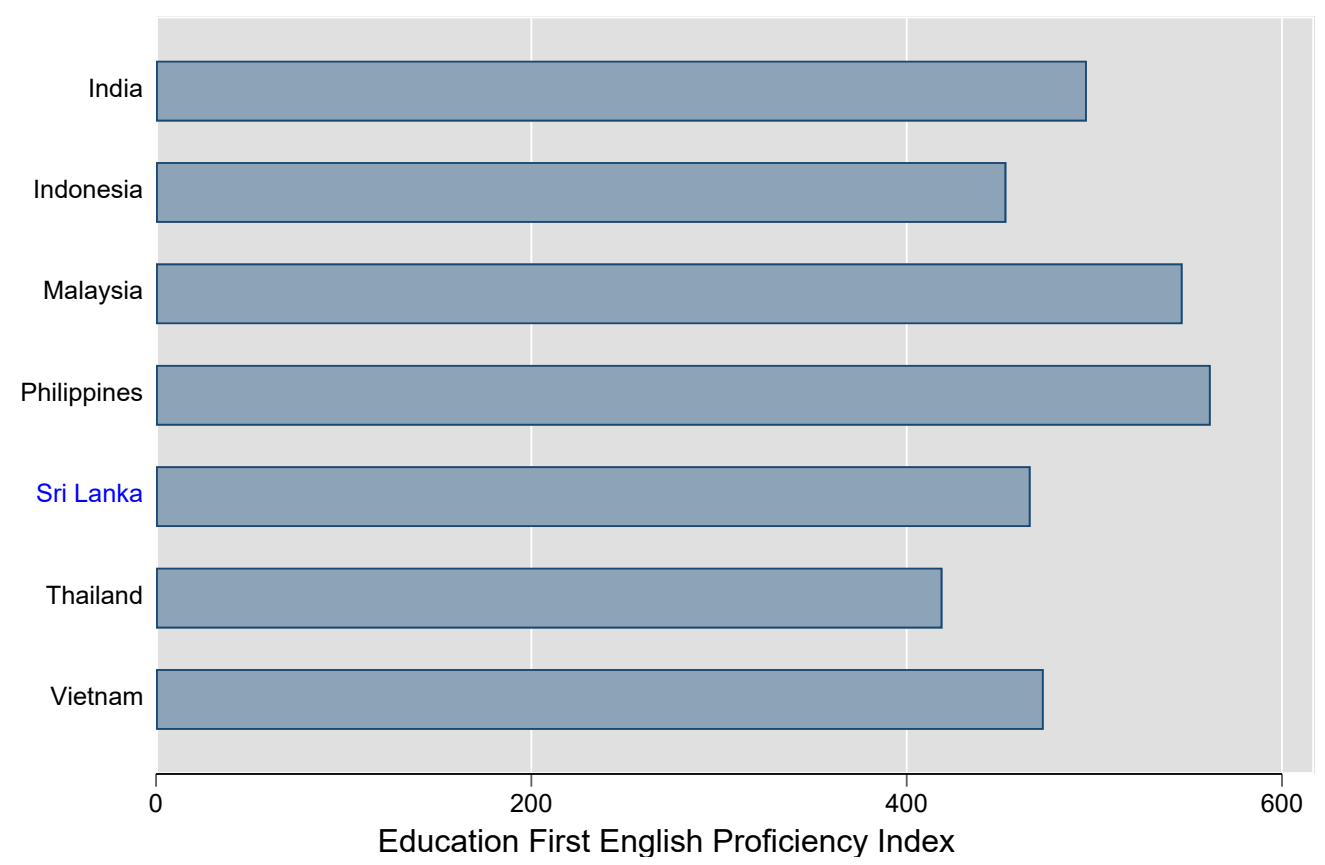

Source: Author's calculations based on a database from Education First.

The emerging economies of South- and South-East Asia present a unique opportunity to tap into the qualified English-speaking workforce and harnessing this opportunity has never been easier with continued improvements in communication technology. In the latest Digital 2021 report (Kemp, 2021), We Are Social estimates that 6 in 10 people around the world currently use the internet. As seen in Figure 6, while half the population in India and Sri Lanka use the internet, this has grown rapidly over the recent years. In India, the internet users have doubled in 4 years, and Sri Lanka has witnessed a 50 percent increase. The penetration and adoption of internet technology are higher in South-East Asia with Malaysia taking the lead at 83 percent, followed by Thailand, Vietnam, and the Philippines. 


\section{Figure 6: Internet usage}

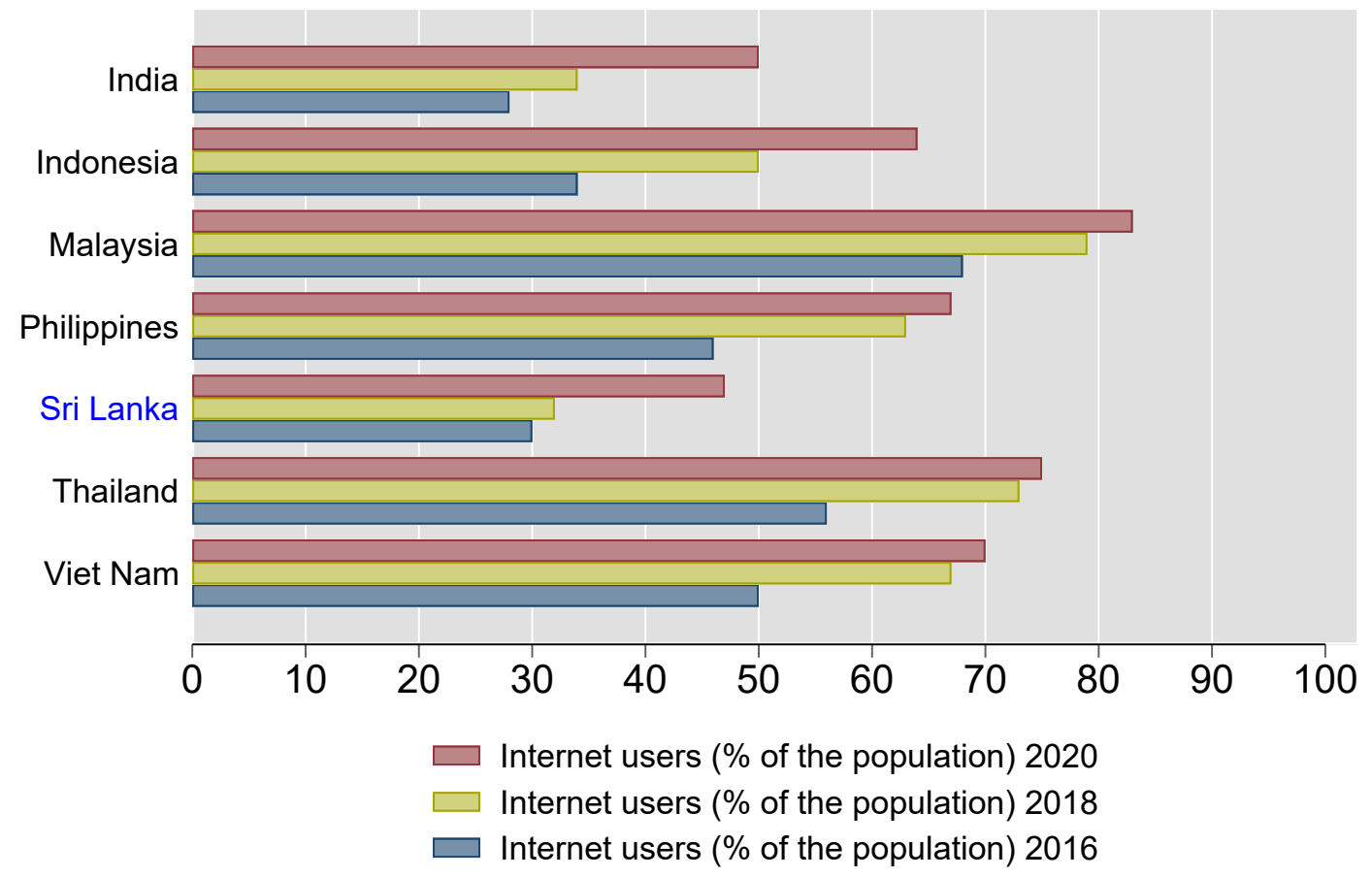

Source: Author's calculations based on Simon Kemp's Digital 2021 Country reports.

As such, the emerging markets of South- and South-East Asia represent a potential route to fulfil the demand gap in the tutoring market in the UK by supplying qualified tutors to provide online tutoring to students, especially the disadvantaged ones, at reasonable costs. This is in conjunction with providing employment opportunities with fair and competitive salaries to qualified graduates in the emerging economies. 


\section{Evidence from Case Study: Third Space Learning in Sri Lanka}

Third Space Learning (TSL) was established in 2013 to work in partnership with schools to make one-to-one maths tutoring accessible to those children with the greatest need, thereby allowing the equality of opportunity. TSL has delivered tutoring sessions to over 90,000 students in over 2,800 state schools, 45 percent of whom were eligible for Pupil Premium. A central part of their vision to ensure equitable access is fulfilled through recruiting high-quality maths tutors from across the emerging markets - notably India and Sri Lanka - where there is a huge population of well-educated English-speaking STEM graduates.

All TSL tutors are undrgratuates or graduates, and go through an extensive training programme before they begin, and receive regular coaching and feedback through Continuous Professional Development (CPD). This helps to provide affordable quality tutoring for students in the UK as well as job opportunities for qualified tutors in India and Sri Lanka.

Here we focus on the TSL subsidiary in Sri Lanka (also known as Third Space Global or TSG) and provide insights on their process of delivering quality tutoring.

\subsection{Hiring, Initial Training, and Continuous Professional Development}

In response to the increasing demand for tutoring from schools in the UK, TSL faced no supply constraint in ramping up its tutor workforce in Sri Lanka. The unemployment rate in the Sri Lankan highly qualified labour market has featured as an oversupply of tutors for TSL in Sri Lanka. Between January 2021 and May 2021, TSL received 13,844 applicants for about 513 tutor vacancies, a selection rate of merely 3.71 percent. As a result of the readily available qualified workforce, TSL has increased its supply in Sri Lanka from 223 tutors in September 2020 to 648 tutors by July 2021 (see Figure 7 ). 


\section{Figure 7: Cumulative number of tutors joining TSL in Sri Lanka}

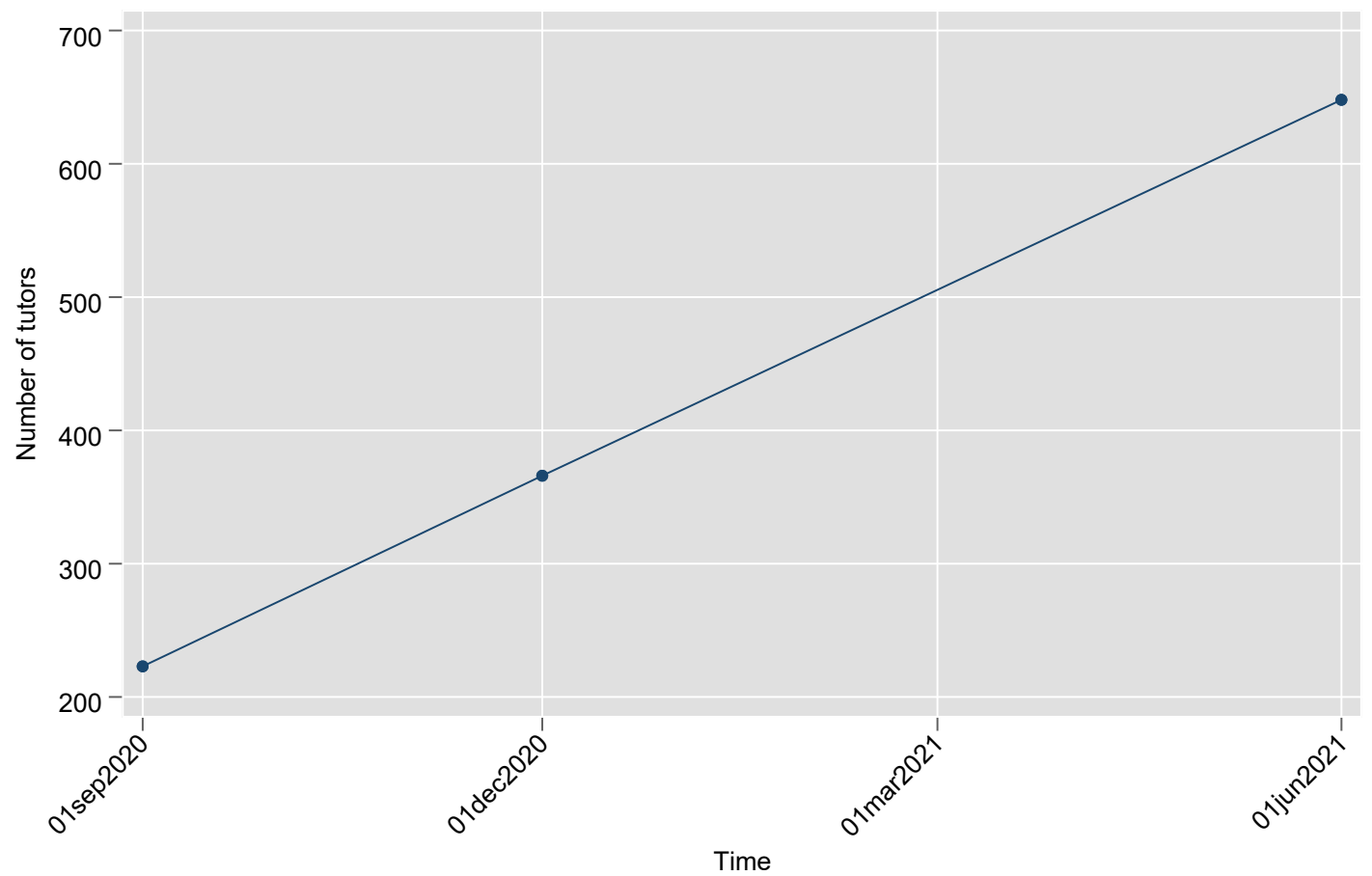

Source: TSL provided data.

To ensure quality in the selection of its tutors, TSL uses a rigorous interview process. Figure 8 illustrates these comprehensive steps with details on how many candidates passed each round using the data from January 2021 to May 2021. As a first step, applications are screened to meet minimum requirements, including background checks (equivalent to DBS checks in the UK). Roughly 63 percent of the applicants pass this step and are invited to complete an online test measuring maths and English abilities. 44 percent of those invited to complete the test, pass the test and progress to Step 4 where an interview is held remotely. This interview helps in understanding the applicant's attitude, personality fit, and enthusiasm for the role. Applicants who pass this stage, progress to Step 5 for a teaching skillsbased interview. During this stage, the applicants are assessed on their teaching ability, subject knowledge, and student-centred teaching. 45 percent of those invited for the teaching assessment pass this stage and are enrolled into initial tutor training which runs for 46 hours over three weeks at no cost to the tutors. Tutors are trained and assessed in student-centred teaching, safeguarding and protection of student data, special educational needs, mathematical anxiety, and teaching in line with the UK curriculum. Of those enrolled on the Initial Tutor Training (ITT), only 38 percent successfully pass the training criteria and are ready to deliver tutoring sessions. 


\section{Figure 8: Hiring journey at TSL in Sri Lanka}

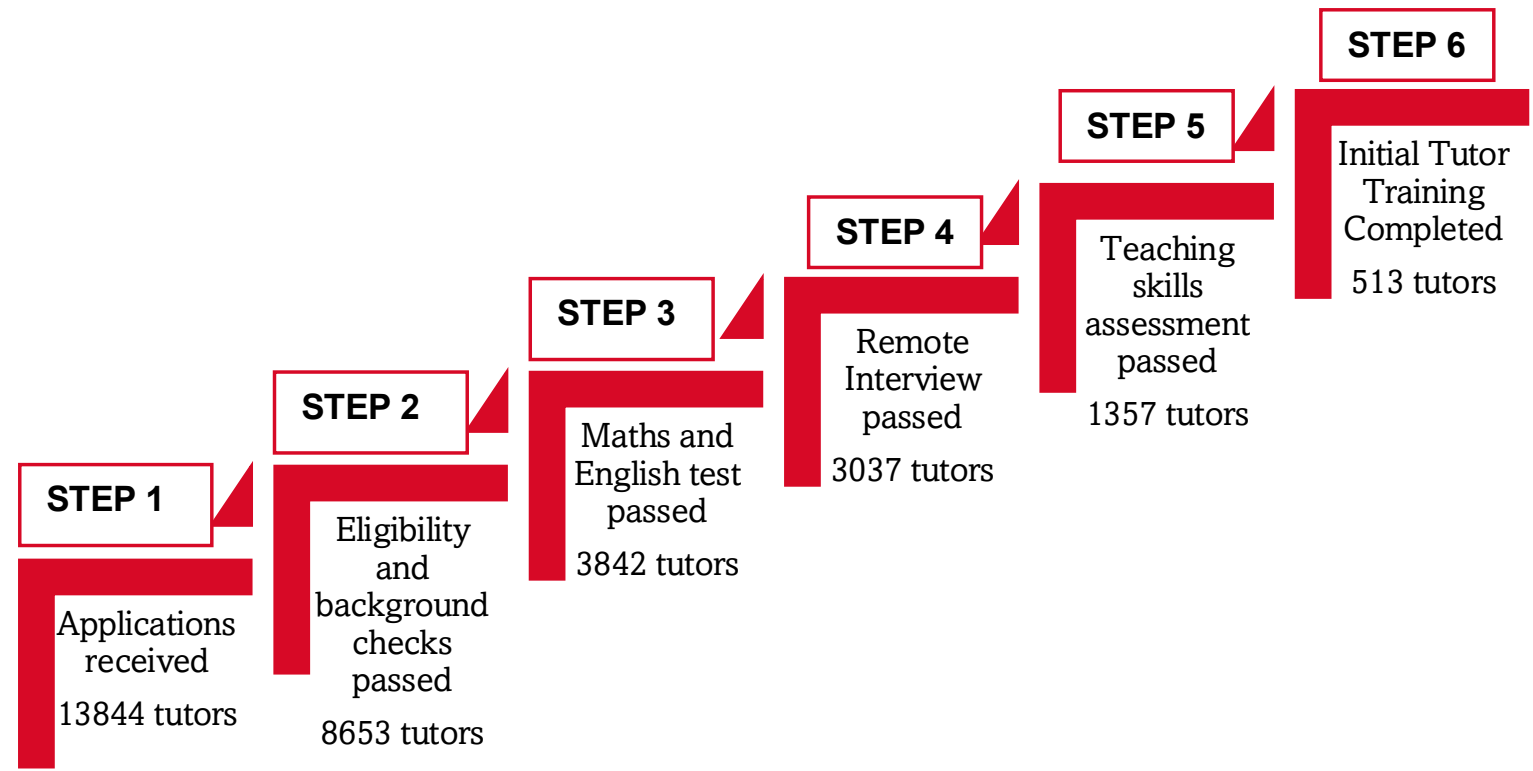

Source: Authors' calculations based on TSL data on all recruitment drives between January 2021 and May 2021.

While there is no comprehensive research on tutor training or even a formal UK requirement that tutors need any training/certification, the ITT provided by TSL is intense at 46 hours over three weeks. We provide a quick comparison with two UK based tutor training providers who are also endorsed by the Tutor's Association in the UK. ${ }^{10}$

- The Level 3 Award in Tutor Training Theory 'PRESET' provided by Myelin Academia is an 8-hour course at a cost of $£ 120$ to the tutor.

- The Level 3 Qualification for Tutors provided by Qualified Tutor is a 32-hour course at a cost of $£ 260$ to the tutor.

Compared to both, the ITT provided by TSL is longer and comes at no cost to the tutors themselves. In fact, tutors are compensated for their ITT participation.

In a recent Teacher Tapp survey, a quarter of the teachers cited that their biggest concern for tutoring under the ongoing National Tutoring Programme was that the tutors were not adequately trained. ${ }^{11}$ Against this backdrop, while TSL provides 46 hours of ITT, it continues to provide extensive continuous professional development. Ongoing tutor support is provided by Academic Coaches - on average each Academic Coach mentors 30 tutors. Academic Coaches support their tutors through weekly feedback and targeted coaching, and refresher training.

\footnotetext{
10 See the Tutor's Association website for more details on Tutor Training.

${ }^{11}$ Survey ID 1004062, responses from 7288 teachers on February 22, 2021.
} 
TSL tutors are also asked to complete self-reflection modules, identifying things that went well in a tutoring session and things that could be better. This is used to have an effective feedback discussion with Academic Coaches and provide tailored refresher training to tutors every term to upskill their knowledge.

\subsection{Performance Evaluation}

Academic Coaches are also entrusted with session evaluations and performance monitoring of each tutor. A recent study by Cadsbya et al. (2019) demonstrates that performance-ranking feedback has a positive impact on performance among full-time employees. Academic Coaches conduct at least two session evaluations per academic term with each tutor, more may be conducted if the Academic Coach spots a need. Tutoring sessions are chosen randomly, observed by Academic Coaches, and evaluated against four main pillars. First, the familiarity pillar ensures that tutors are aware of the policies and procedures advocated at TSL. The second is subject knowledge - the tutor's mathematical knowledge, and the ability to identify various approaches to teaching a concept and to spot mistakes and misconceptions. Third, the effective communication pillar ensures that tutors deliver lessons with clear communication. Finally, student-centred teaching ensures tutors understand and identify the domains of a child's learning, and are able to tailor tutoring sessions to the child's needs. Each tutor is rated on their performance on these four pillars twice per academic term.

\section{Table 1: Performance pillars from tutor's session evaluation at TSL in Sri Lanka}

\begin{tabular}{|c|c|c|c|}
\hline Pillar & Share & Key performance indicators & Score \\
\hline Familiarity & $21 \%$ & $\begin{array}{l}\text { Familiarity } \\
\text { Launching on time } \\
\text { Uncompleted Post Feedback Reports }\end{array}$ & $\begin{array}{l}12 \% \\
4 \% \\
5 \%\end{array}$ \\
\hline Subject Knowledge & $16 \%$ & Subject Knowledge & $16 \%$ \\
\hline $\begin{array}{l}\text { Effective } \\
\text { Communication }\end{array}$ & $21 \%$ & $\begin{array}{l}\text { Effective Communication } \\
\text { Understandability }\end{array}$ & $\begin{array}{l}13 \% \\
8 \% \\
\end{array}$ \\
\hline $\begin{array}{l}\text { Student-Centred } \\
\text { Teaching }\end{array}$ & $42 \%$ & $\begin{array}{l}\text { Student-centred Teaching } \\
\text { Enjoyability } \\
\text { Independence } \\
\text { Usefulness } \\
\text { Tutor Availability }\end{array}$ & $\begin{array}{l}17 \% \\
6 \% \\
6 \% \\
6 \% \\
7 \% \\
\end{array}$ \\
\hline
\end{tabular}

Source: Information based on TSL in Sri Lanka documents provided by the Quality Assurance Support Team. 
Monitoring tutoring efficacy is important not just to ensure session quality, but also for student performance. Research on classroom teaching shows that what matters most for student performance is teaching efficacy (Klassen and Tze, 2014). Similarly, one can think that this would hold for tutoring, a form of teaching, as well. Based on the performance pillars, the average session evaluation score is 80 out of 100 . It is worth mentioning that the minimum evaluation score of the tutoring sessions is 65 out of 100 , which reflects the high quality of CPD through feedback and coaching at TSL in Sri Lanka. We also look at the average session evaluation scores by the four performance pillars in Figure 9. The average score is above 80 out of 100 on familiarity, effective communication, and student-centred teaching. When it comes to subject knowledge, the average score is lower at 78 percent, but still very high. These patterns are the same regardless of the education levels. This evidences the skills development and valuable experience that these tutors receive while working for TSL.

\section{Figure 9: Tutor session evaluation score (out of $100)$ by performance pillars}

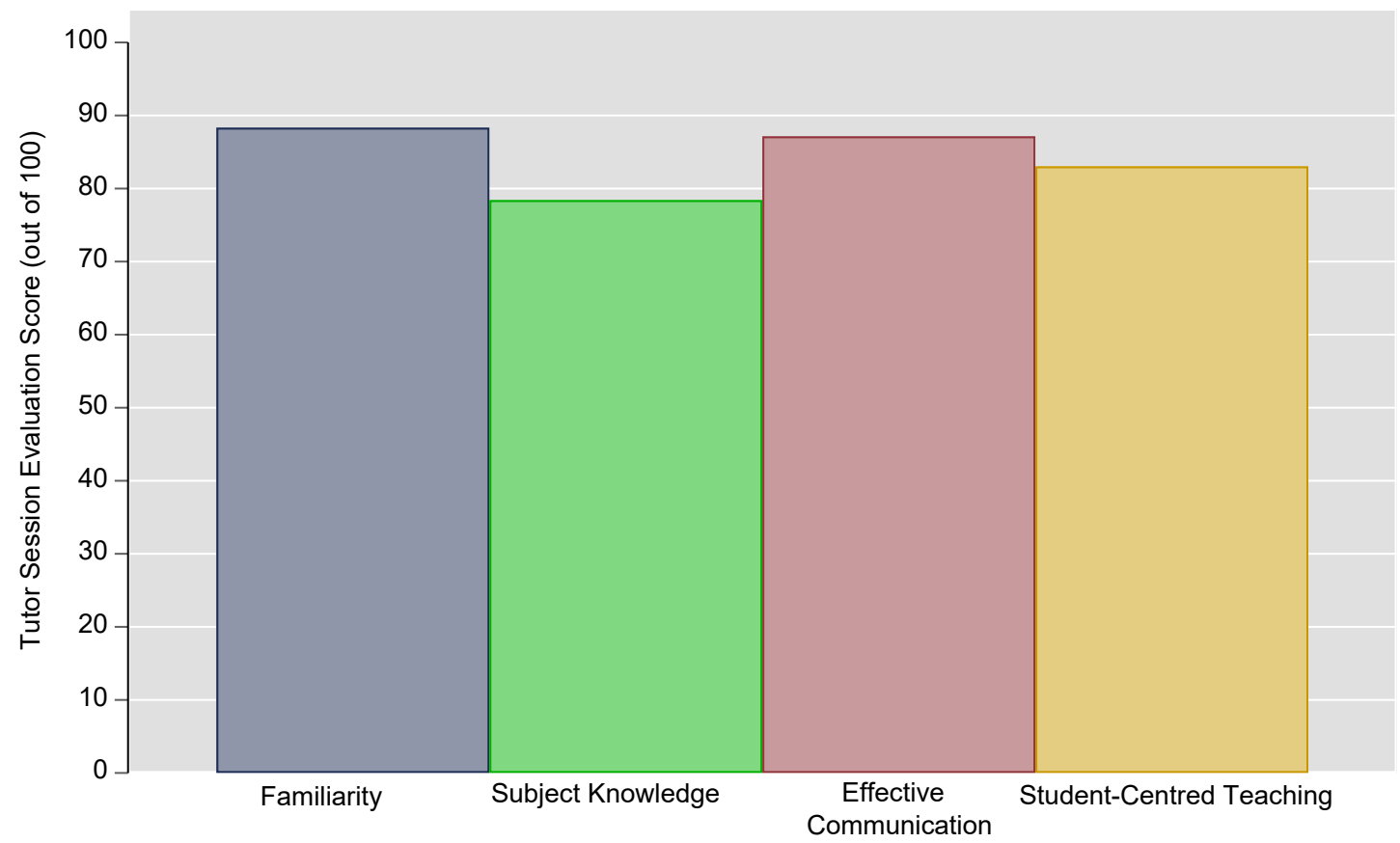

Source: Author's calculations based on a database of 657 tutors working for TSL in Sri Lanka. The session evaluation scores were averaged over 4 evaluations conducted during academic terms 1 and 2 in 2020-2021. 


\subsection{Safeguarding}

TSL in the UK (non-tutor staff) and TSL in Sri Lanka (tutor staff) are committed to child safeguarding, with an extensive safeguarding policy created in partnership with the National Society for the Prevention of Cruelty to Children (NSPCC) which is reviewed annually..$^{12}$ Here we summarise the steps in brief -

- Recruitment stage: All tutors undergo a series of background checks, including reference checks and police verification. They also undergo rigorous interviews to determine the tutor's suitability to work with children (also see Section 3.1 and Figure 8 for details).

- Initial Tutor Training: All tutors are provided with safeguarding training and tested on their knowledge of this at the end of the ITT. Tutors must pass the ITT assessment in order to be hired.

- Continuous Professional Development: All tutors receive weekly feedback and refresher training, including familiarity with TSL's safeguarding policy.

- Performance evaluation: Academic Coaches randomly select tutor session recordings for evaluation, a key aspect of which is evaluating the tutors on their familiarity with TSL's policies. Evaluations are conducted at least twice every academic term.

- Tutoring Sessions: All sessions are recorded to ensure that tutors adhere to the safeguarding policies and procedures. There is also real-time monitoring by a Supervisor, provided by the school who is present in the room with the child during the session. Additionally, TSL has a dedicated Quality Assurance Team that can listen in live to any session. Tutors interact with children online only through the TSL platform at the times agreed on between the child's school and TSL. Access to the platform is through unique usernames and passwords that are regularly changed. The interaction online is only through voice and there is no mechanism for a camera to transmit images or videos.

\subsection{Tutor Qualifications}

Looking at the education profile of all 657 tutors working for TSL in Sri Lanka, we find that there is a high degree of STEM specialisation among the TSL tutors in Sri Lanka - 67 percent have specialised in STEM or maths-related disciplines at university (Figure 10).

\footnotetext{
12 The full policy can be accessed on the TSL website.
} 


\section{Figure 10: Educational Qualifications of TSL tutors in Sri Lanka}

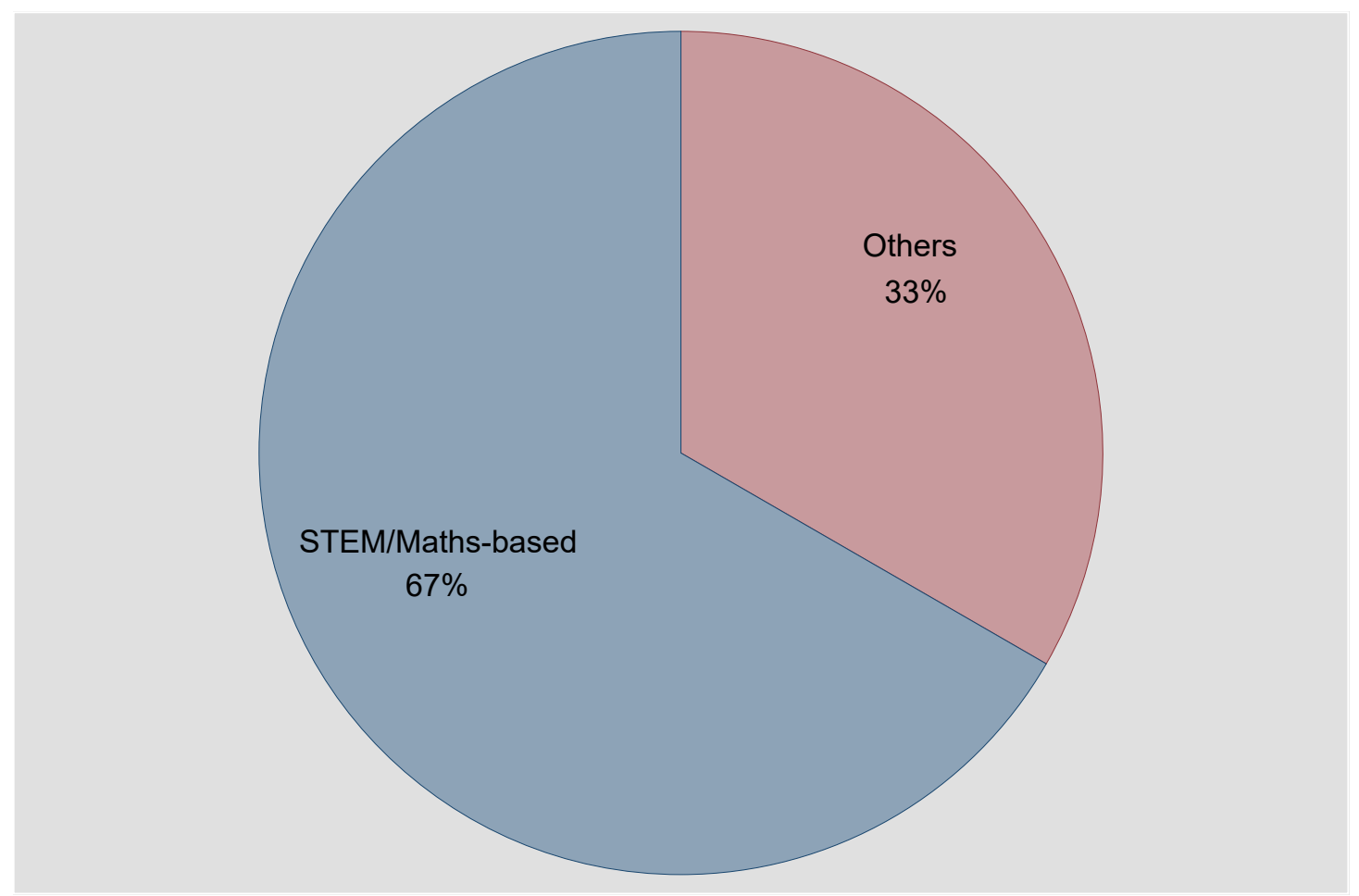

Source: TSL provided data.

\subsection{Tutor Motivation}

Given that a significant proportion of tutors are pursuing university degrees while working at TSL, it is unsurprising that in a survey of 499 TSL tutors, we found that 24 percent of the tutors joined TSL to fund their studies. As seen in Figure 11, only 9 percent of the tutors use the tutoring job at TSL as a full-time job; instead, they use it as a complementary source of income. About 20 percent use it as a source of extra income and another 17 percent use it to gain job experience. 


\section{Figure 11: Tutor motivation to work at TSL in Sri Lanka}

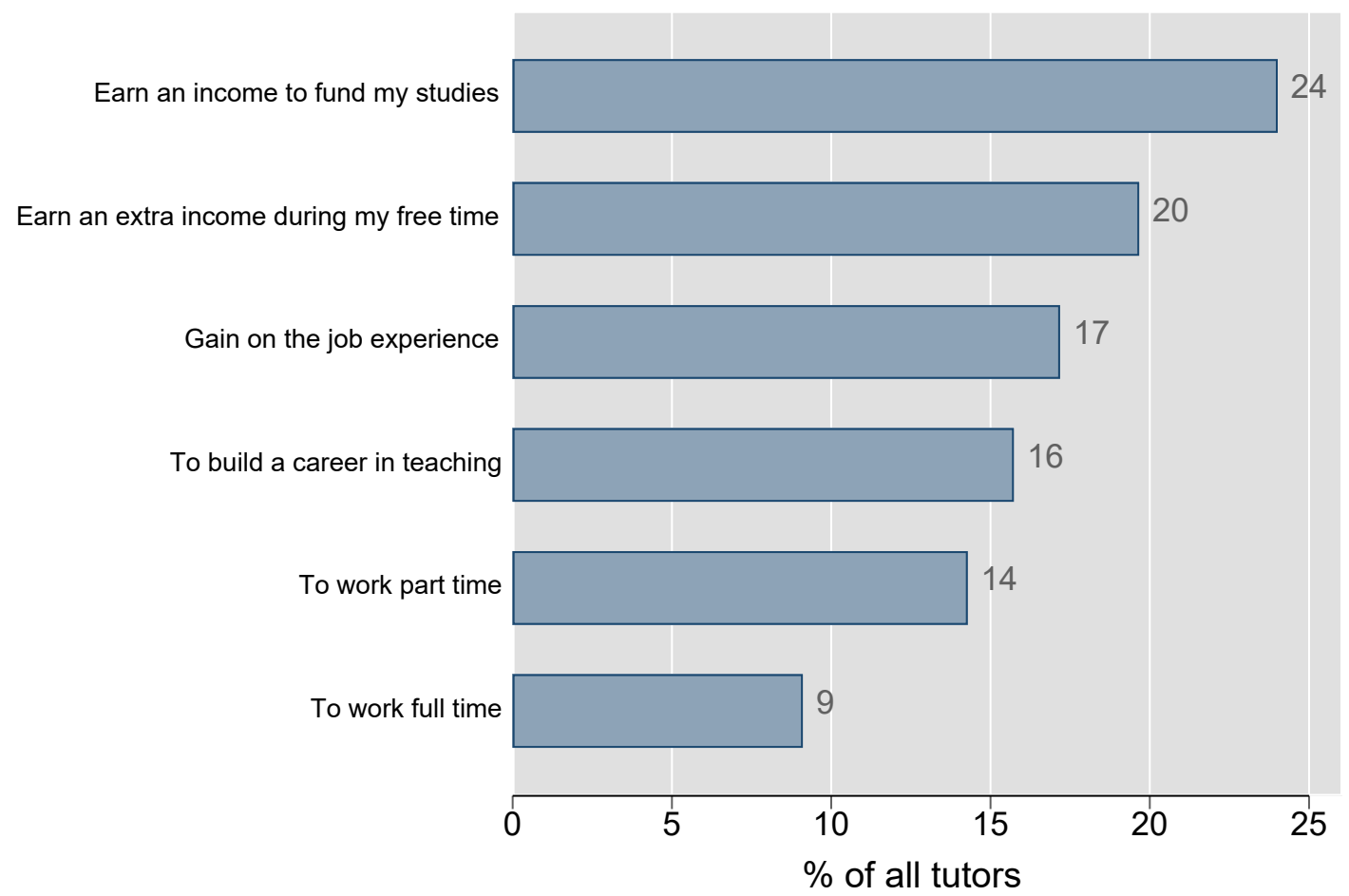

Source: Author's calculations based on a survey of 499 tutors working for TSL in Sri Lanka conducted in May 2021.

On average, a TSL tutor works 15 hours a week and 75 percent of the tutors are part-time, working 20 hours or less in a week. Given the flexible nature of working for TSL, it attracts qualified women who use this as an opportunity to work flexible hours and supplement their family income. About 76 percent of all TSL tutors are women. This is a great advantage for women in South- and South-East Asia who typically face a major gap along several socio-economic dimensions.

"As a working mother, I am happy to work with TSG [the TSL subsidiary in Sri Lanka].... they are understandable and helpful."

"This [working as a tutor] has been a life-changing experience to me as a mother of an infant. The exposure, professional training and development activities, the comfort of working from home has all turned out to be of tremendous support. TSG [the TSL subsidiary in Sri Lanka] has been one of the main reasons for me to stand out as a support for my family in all possible means as a daughter, as a wife and as a mother." 
The flexible nature of the work and the part-time component makes working from home highly desirable and preferred among the TSL tutors. In a recent survey, 472 TSL tutors were asked to rate their level of satisfaction with the TSL's work environment, where 0 represented the worst score and 10 the highest. In Figure 12 , we find that almost all tutors appreciated the benefit of working remotely. 97 percent of the tutors rated the opportunity to work from home at seven or higher. The work-from-home setting is not as common in most developing countries as in the developed world (Berg, Bonnet and Soares, 2020). Working from home can help the tutors enhance productivity and reduce work-family conflict (Kelly et al., 2014). A study by Bloom et al. (2015) measured the performance of workers in a call centre who were assigned to work from home. They found that working from home increased performance, led to higher work satisfaction, and lower turnover.

\section{Figure 12: Tutor perception of flexibility at TSL in Sri Lanka}

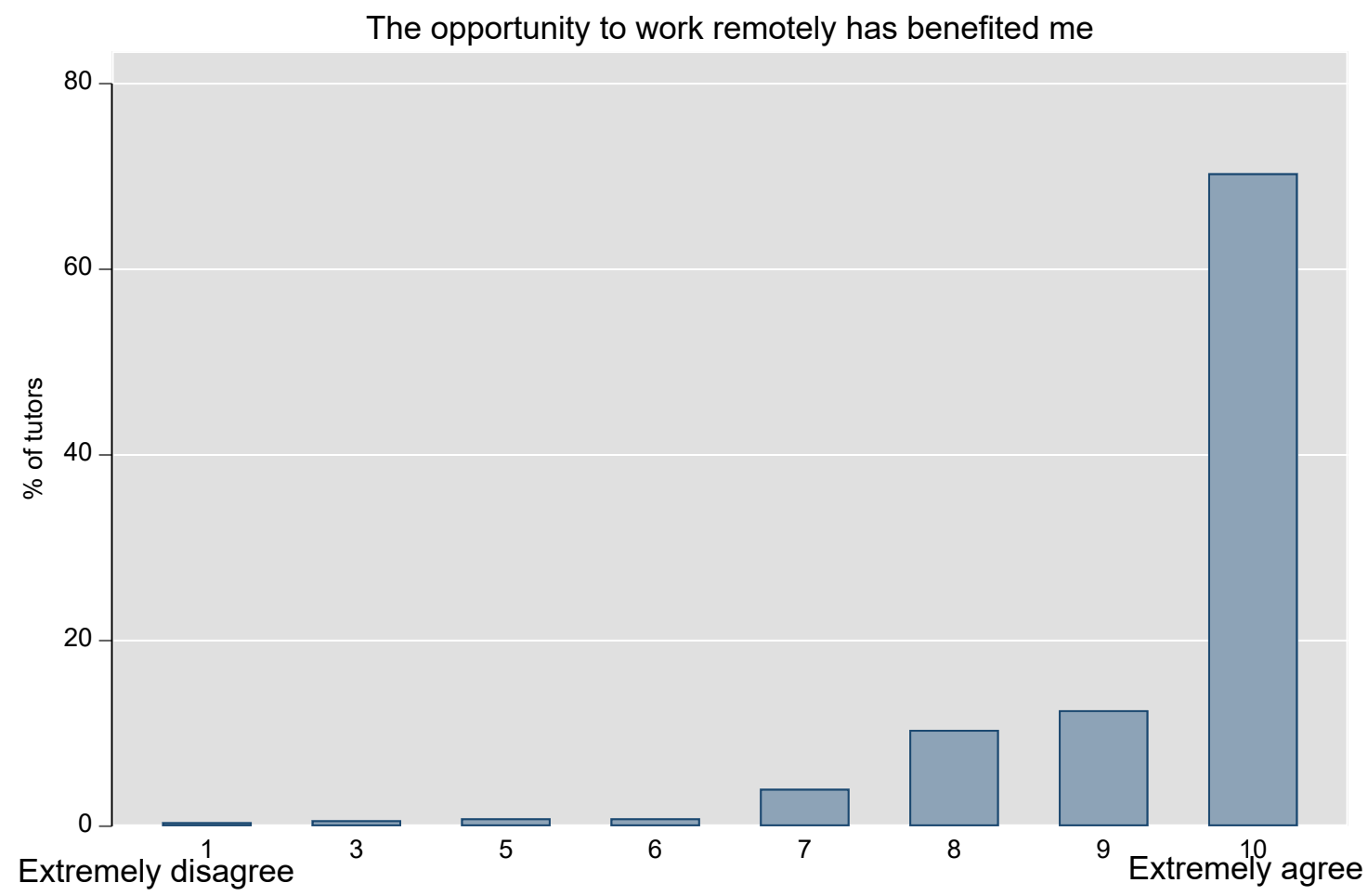

Source: Author's calculations based on a survey of 472 tutors working for TSL in Sri Lanka, conducted in June 2021.

\subsection{Tutor Pay}

TSL pays an average of $£ 3.07$ per hour to its tutors which is 17 times the Sri Lankan minimum wage and 2.8 times the average salary of skilled and semi- 
skilled workers in Sri Lanka. ${ }^{13}$ The TSL pay adjusted for the cost of living using PPP, is equivalent to $£ 9.60 /$ hour. ${ }^{14}$ While this is half of what a tutor in the UK earns, as already illustrated, the pay in the local Sri Lankan market represents a significant premium. Consider a hypothetical scenario where the TSL tutor pay were to double to $£ 6.14$ or roughly $£ 20$ in PPP terms, this would equalise the real pay (adjusted for cost of living) in the UK and Sri Lanka. However, this would have grave implications for the Sri Lankan economy and human capital development, where working as a tutor would become economically more attractive than specialising as a doctor, engineer, or teacher. Over time, if enough companies acted on this, the consequence would be deskilling of the Sri Lankan workforce in the long-run. Hence, while TSL pay of $£ 3.07$ may not be equivalent to what a UK tutor earns, it is more than a fair and competitive wage in the local economy.

This TSL pay-premium also comes out as a significant source of satisfaction among TSL tutors.

"Along with the satisfaction gained TSG [TSL subsidiary in Sri Lanka] does not fail to give us the benefits we wouldn't receive elsewhere as the pay is quite high comparatively..."

Source: Qualitative feedback from a survey of 499 TSL tutors conducted in May 2021.

Consistent with that, tutors expressed a positive attitude towards TSL's pay structures and benefits. In the same survey of 472 tutors, tutors were asked to rate their level of satisfaction with the TSL's pay structure, where 0 represented the worst score and 10 the highest. As shown in Figure 13, while less than five percent of tutors think that the pay structure and growth benefits are not sufficiently great, the majority appreciate it. Indeed, 84 percent of the tutors agree with the statement of great pay structures and benefits provided by TSL (score of 7 or above).

${ }^{13}$ The average monthly pay of a full-time salaried worker in Sri Lanka is $£ 177$ (49,229 SLR) as estimated by the Sri Lankan Department of Census and Statistics: Labour Force Survey in 2019. The minimum daily wage is set at $£ 1.45$ (400 SLR) by the Sri Lankan National Mimum Wage of Workets Act, No. 3 of 2016.

14 The PPP calculation are based on the data from Our World in Data 


\section{Figure 13: Tutor perception of pay at TSL in Sri Lanka}

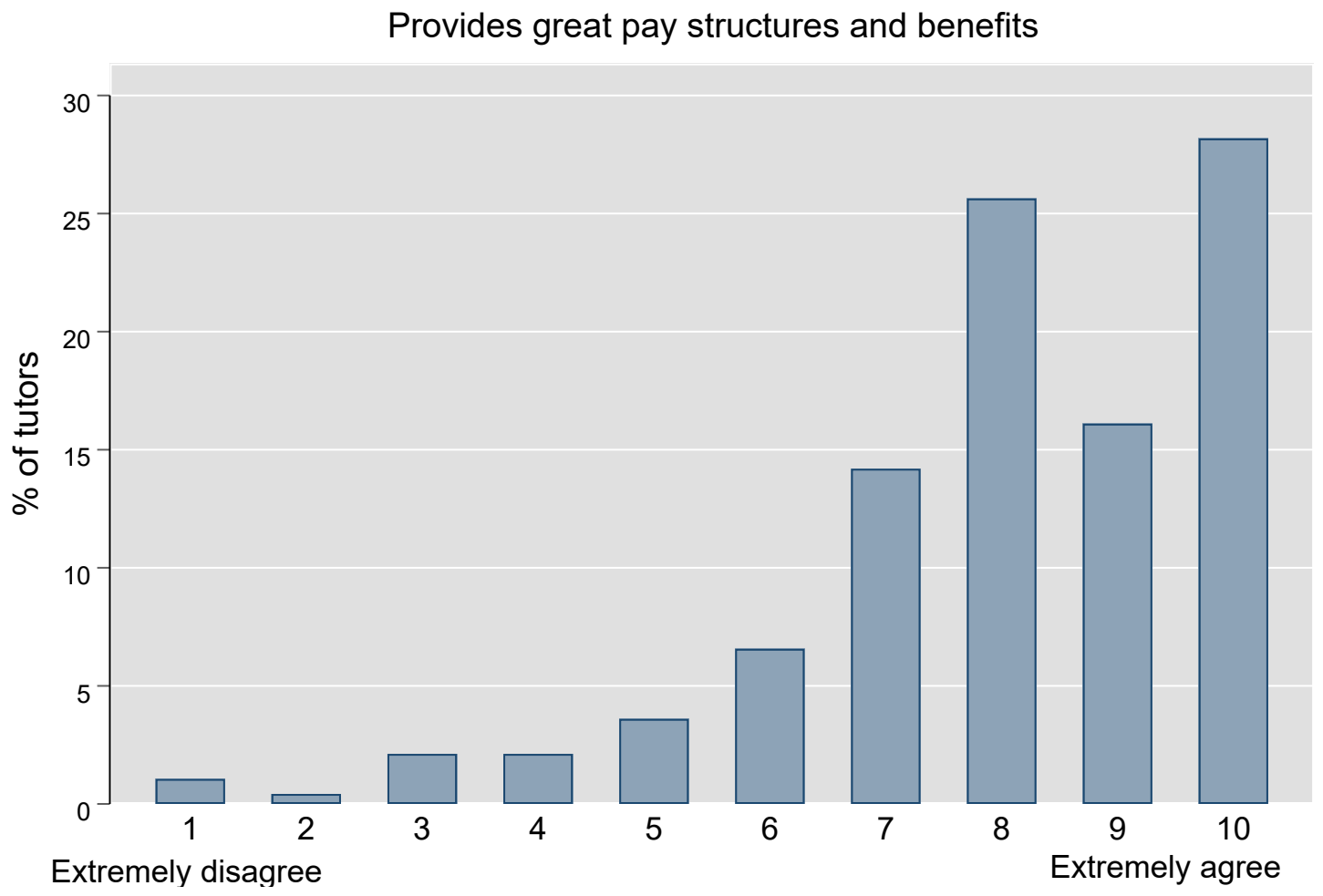

Source: Author's calculations based on a survey of 472 tutors working for TSL in Sri Lanka, conducted in June 2021.

\subsection{Work Environment and Tutor Satisfaction}

TSL's commitment to its tutors' continuous professional development, feedback, and coaching is highly valued by the tutors.

"I find consistent growth in myself as a result of the mindset instated in it by the training [..provided by TSL in Sri Lanka]. The feedbacks help me improve a lot as a person and an employee."

"I love to work with TSG [the TSL subsidiary in Sri Lanka] and I feel satisfied......Because my team and my supervisor have helped me a lot to improve my performance....Although some sessions are challenging I have the potential to manage it because of my supervisor's encouragement." 
A recent study by Bakotić (2016) found that job satisfaction is a key determinant of overall performance. In a survey of 472 TSL tutors, tutors were asked to rate their level of satisfaction with TSL's professional support, where 0 represented the worst score and 10 the highest. The survey found that on all statements related to professional development and support, the average score provided by tutors was above 8 (out of 10). As shown in Figure 14, only a few tutors rated these statements as low (below 6).

\section{Figure 14: Tutor perception of training and feedback at TSL in Sri Lanka}
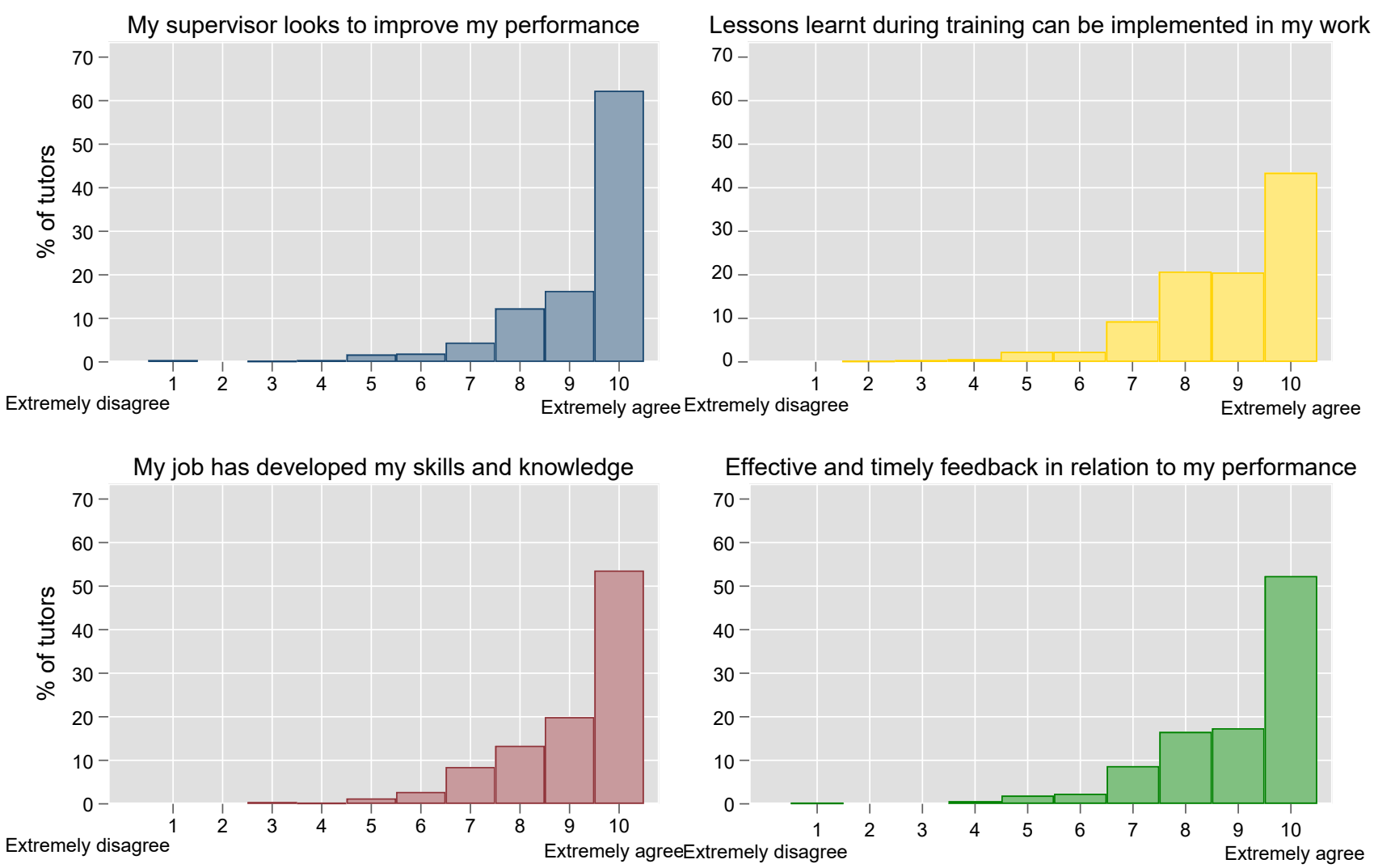

Source: Author's calculations based on a survey of 472 tutors working for TSL in Sri Lanka, conducted in June 2021.

In the same survey of 472 TSL tutors, another aspect identified as a source of satisfaction among tutors was the ease with which they could communicate with the management.

"I] like its [TSL's] modern approach of managing the company. Like how everyone is given a chance to voice their opinion and how everyone is valued. And how approachable the management is." 
In Figure 15, we present the tutor's level of satisfaction regarding their communication with the management. On all aspects of the communication, the average was 8 (out of 10). 85 percent of the tutors are extremely eager to join meetings and briefings (score of 7 or above); 93 percent are highly satisfied with the level of communication and management (score of 7 or above); and 92 percent find the management to be approachable (score of 7 or above).

\section{Figure 15: Tutor perception of communication within TSL in Sri Lanka}
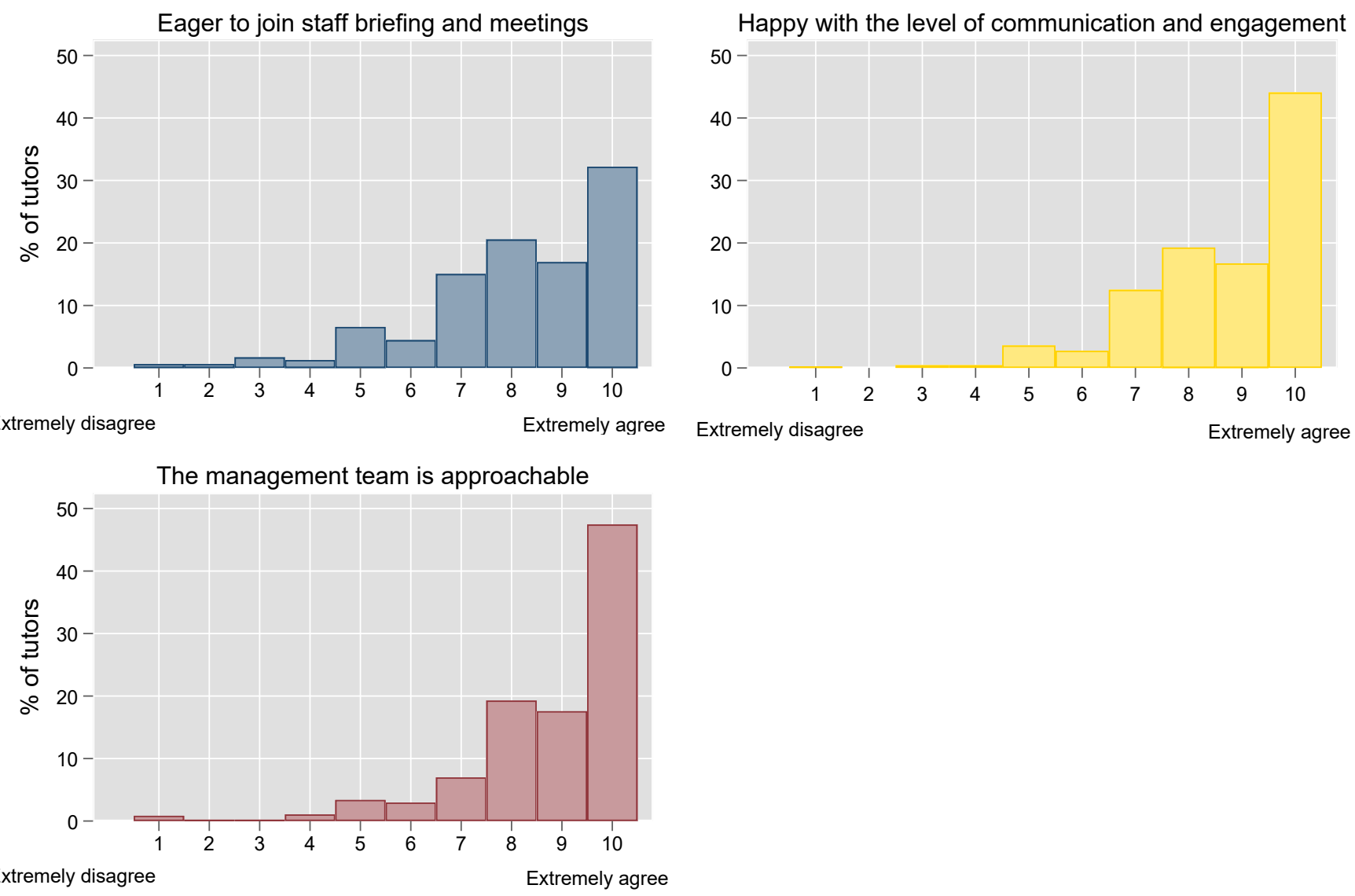

Source: Author's calculations based on a survey of 472 tutors working for TSL in Sri Lanka, conducted in June 2021.

Given the high levels of tutor satisfaction with various aspects of TSL, it is unsurprising that tutors enjoy their work and workplace and are proud to be a part of the TSL community. While 90 percent of the tutors enjoy the work they do for TSL (score of 7 or above), at least 95 percent are proud to be part of the TSL (score of 7 or above) and find TSL to be a great place to work (see Figure 16). Nearly none 'extremely disagree' with these statements related to their job satisfaction within TSL. 


\section{Figure 16: Tutor perception of job satisfaction at TSL in Sri Lanka}
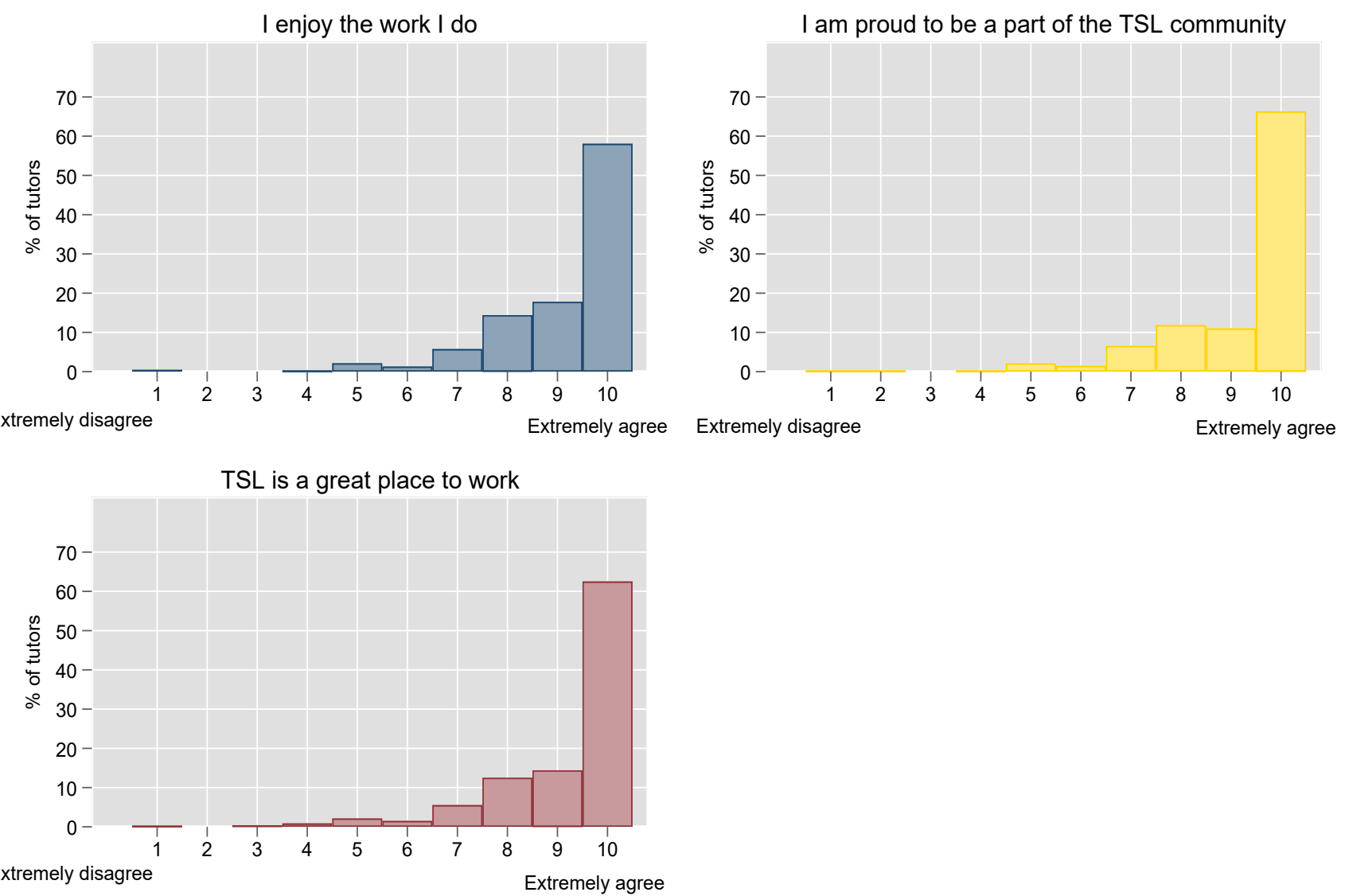

Source: Author's calculations based on a survey of 472 tutors working for TSL in Sri Lanka, conducted in June 2021. 


\section{Conclusion}

This report sets out to address the viability of an innovative tutoring delivery model that brings affordable one-to-one tutoring to the UK schools. In the aftermath of COVID-related school closures in the UK, students lost two months of learning with the loss among the disadvantaged student group being much larger at seven months. This disadvantaged gap is almost entirely driven by maths attainment.

While the Government has committed an estimated $£ 180$ million for the NTP to provide 15-hour tutoring courses to 500,000 of the 1.7 million disadvantaged students in the 2021/22 academic year, it is likely to fall short. ${ }^{15} \mathrm{~A}$ study by the Centre for Economic Performance estimates that at least 100 hours of tutoring over a year will be needed to compensate for the COVID-related learning losses (Eyles, Gibbons, and Montebruno, 2020). With the one-to-one tutoring cost at an average of $£ 46$ per hour under the NTP and 1.7 million Pupil Premium eligible students, we are looking at an investment of $£ 7.8$ billion. ${ }^{16}$ This suggests that traditional tutoring models lack the scale and affordability that is needed.

A potential route to providing affordable tutoring sessions is utilising the skills of a highly qualified labour force in the emerging economies of South- and South-East Asia. Besides having an advantage in English language skills as well growing access to internet technology, these emerging economies collectively produce the highest number of STEM graduates. However, these graduates continue to face a lack of job opportunities in the local market with unemployment rates as high as 15 percent in India. Given the labour market challenges, it is unsurprising that graduates find providing online tutoring to students in high-income countries a worthwhile opportunity.

Third Space Learning (TSL) represents an example of how the qualified Englishspeaking labour force can be trained to provide high-quality tutoring support at an affordable price in the UK, ensuring equitable social impact in both Sri Lanka and the UK. Through an intensive 6-stage hiring process, a mere 3.7 percent of applicants are selected to work as TSL tutors in Sri Lanka. Even though there is no formal tutor training required by the UK Government, TSL invests in all its tutors through a 46-hour Initial Tutor Training (ITT) course at no cost to the tutors themselves. The TSL commitment to its tutors' growth does not stop with the ITT. TSL tutors are provided with continuous professional development in the form of weekly feedback and termly refresher training. TSL tutors are also regularly evaluated (six times in an academic year) based on their familiarity with TSL

\footnotetext{
15 See the NTP funding allocation for AY 2021/2022.

${ }^{16}$ The average tutoring cost per hour is calculate using the NTP Tuition Partners who provide 1:1 tutoring. Where in-person and online tutoring rates were different, the lower of the two was used for calculation.
} 
safeguarding procedures, subject knowledge, communication skills, and studentcentred teaching.

One of the main conclusions of the TSL case study is the high levels of satisfaction among TSL tutors along several dimensions. Tutors appreciate the pay structure and the benefits provided by TSL. At an average hourly pay of $£ 3.07$, the TSL tutor salary is estimated at 2.8 times the Sri Lankan salary for skilled and semi-skilled workers, representing a significant premium over the local labour market pay.

This report demonstrated how TSL achieves a win-win situation on both the demand (UK) and supply side (Sri Lanka) of their tutoring model. They are able to not only deliver affordable tutoring through highly qualified and motivated tutors to the disadvantaged students in the UK but also create income and employment opportunities for graduates in Sri Lanka. 


\section{References}

Angrist, N., Djankov, S., Goldberg, P. K., \& Patrinos, H. A. (2021). Measuring human capital using global learning. Nature, 592, 403-408.

Bakotić, D. (2016). Relationship between job satisfaction and organisational performance. Economic Research-Ekonomska Istraživanja, 29(1), 118-130.

Berg, J., Bonnet, F., \& Soares, S. (2020). Working from home: Estimating the worldwide potential. London: VoxEu

Bloom, N., Liang, J., Roberts, J., \& Ying, a. Z. (2015). Does Working from Home Work? Evidence from a Chinese Experiment. The Quarterly Journal of Economics, 165-218.

Cadsbya, C. B., Songb, F., Engle-Warnick, J., \& Fangd, T. (2019). Invoking social comparison to improve performance by ranking employees: The moderating effects of public ranking, rank pay, and individual risk attitude. Journal of Economic Psychology, 64-79.

Ciano, L. (2007). Online Tutoring and the Offshoring of Education. TCC 2007 Proceedings.

Davies, S. (2004). School Choice by Default? Understanding the Demand for Private Tutoring in Canada. American Journal of Education, 110(3), 233-255.

Department for Business, E., \& Strategy. (2017). Industrial strategy: building a Britain fit for the future.

Department for Education. (2019). Initial Teacher Training (ITT) allocations and the Teacher Supply Model (TSM), England 2020 to 2021. London: Department for Education.

Education First. (2020). EF English Proficiency Index: A Ranking of 100 Countries and Regions by English Skills. London: Education First (EF).

Eyles, A., Gibbons, S., \& Montebruno, P. (2020). Covid-19 school shutdowns: What will they do to our children's education?. CEP Covid-19 Briefings cepcovid-19-001, London: Centre for Economic Performance, LSE.

Ireson, J., \& Rushforth, K. (2014). Why do parents employ private tutors for their children? Exploring psychological factors that influence demand in England. Journal for educational research online, 6(1), 1233.

Kara, E., Tonin, M., \& Vlassopoulos, M. (2021). Class size effects in higher education: Differences across STEM and non-STEM fields. Economics of Education Review, 82, 102104.

Kelly, E. L., Moen, P., Oakes, J. M., ...., \& Casper, L. (2014). Changing Work and Work-Family Conflict: Evidence from the Work, Family, and Health Network. American Sociological Review, 79(3), 485-516.

Kemp, S. (2021). Digital 2021 April Global Statshot Report. London: DataReportal.

Klassen, R. M., \& Tze, V. M. (2014). Teachers' self-efficacy, personality, and teaching effectiveness: A meta-analysis. Educational research review, 12, 59-76.

Lucas, M., Nelson, J., \& Sims, D. (2020). Pupil engagement in remote learning. National Foundation for Educational Research Report. London: National Foundation For Educational Research (NFER).

Means, B., Toyama, Y., Murphy, R., Bakia, M., \& Jones, K. (2009). Evaluation of Evidence-Based Practices in Online Learning: A Meta-Analysis and Review of Online Learning Studies. Washington: U.S. Department of Education.

Menzies, L., Ramaiah, B., \& Boulton, C. (2021). A Space for Maths. Exploring the case for maths tutoring and potential role of Third Space Learning. London: The Centre for Education \& Youth.

Mischo, C., \& Haag, L. (2002). Expansion and effectiveness of private tutoring. European Journal of Psychology of Education volume, 17(3), 263-273.

Richardson, M., Isaacs, T., Barnes, I., Swensson, C., Wilkinson, D., \& Golding, J. (2020). Trends in International Mathematics and Science Study (TIMSS) 2019: National report for England. London: Department for Education.

Sibieta, L. (2020). 2020 annual report on education spending in England. London: The Institute for Fiscal Studies. 
Closing England's Maths Attainment Gap through One-to-One Tutoring - Global Solutions

Worth, J., \& Faulkner-Ellis, H. (2021). Teacher Labour Market in England. London: National Foundation For Educational Research (NFER). 


\section{(-) institute of development \\ studies}

Delivering world-class research, learning and teaching that transforms the knowledge, action and leadership needed for more equitable and sustainable development globally.

Institute of Development Studies

Library Road

Brighton, BN1 9RE

United Kingdom

+44 (0)1273606261

ids.ac.uk

Charity Registration Number 306371

Charitable Company Number 877338

(C) Third Space Learning, 2021 